\title{
Revisiting Cu-based shape memory alloys: Recent developments and new perspectives
}

\author{
E. M. Mazzer ${ }^{1, a)} \oplus$, M. R. da Silva ${ }^{2}$, P. Gargarella ${ }^{2,3}$ \\ ${ }^{1}$ Departamento de Engenharia Metalúrgica e de Materiais, Universidade Federal de Minas Gerais (UFMG), Belo Horizonte, MG, Brazil \\ ${ }^{2}$ Departamento de Engenharia de Materiais, Universidade Federal de São Carlos (UFSCar), São Carlos, SP, Brazil \\ ${ }^{3}$ Centro de Caracterização e Desenvolvimento de Materiais (CCDM), Universidade Federal de São Carlos (UFSCar), São Carlos, SP, Brazil \\ a) Address all correspondence to this author. e-mail: eric.marchezini@demet.ufmg.br ericmazzer@ufmg.br \\ Received: 30 June 2021; accepted: 12 November 2021; published online: 1 January 2022
}

Cu-based shape memory alloys belong to one important class of functional alloys, presenting shape memory effect and superelasticity due to their reversible martensitic transformation. Although they have been extensively studied since the middle of the last century, there are still many challenges to be solved. In the last decades, these alloys were extensively studied regarding new compositions, processing routes, phase transformation, mechanical and functional properties. Aspects of the thermoelastic phase transformation have been described using thermodynamic and thermo-mechanical studies, while the role of metallurgical features (such as grain size and morphology, ordering, precipitates and second phases) have been described mainly by phenomenological approach. In this sense this review discusses the advances in the general fundamentals of $\mathrm{Cu}$-based shape memory alloys, the recent developments in processing routes, compositions, and applications in the last years.

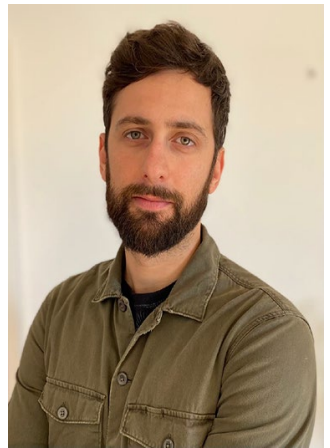

E. M. Mazzer

E. M. Mazzer Professor joined the Department of Metallurgical and Materials Engineering (Demet) at Federal University of Minas Gerais (UFMG), Brazil, in 2016. He received his B.Eng. in the field of Materials Engineering from Federal University of São Carlos-UFSCar/Brazil in 2011, M.S. in Materials Science and Engineering (UFSCar/Brazil, 2013), and Ph.D. in Materials Science and Engineering (UFSCar/Brazil, 2016) with a collaborative period in the Department of Materials at the University of Oxford, UK between 2014 and 2015. His research interests encompass the development and processing of new metallic material, Al-based composites, and shape memory alloys. Prof. Mazzer's research is focused on phase transformation, such as precipitation hardening in $\mathrm{Al}$ alloys and thermoelastic martensitic transformation in Cu-based shape memory alloys. His current work includes unconventional metallic processing involving powder metallurgy and thermomechanical processing of multi-component alloys and their deformation behavior.

\section{Introduction}

The development of smart materials, which react with an external stimulus changing some properties or shape,has been boosted with the advancement of technology in several areas of knowledge. Among these areas, one of great importance is that regarding new and advanced materials development. Shape memory alloys (SMA) can be framed between the new functional materials, which can be used mainly in actuators, microcontrollers and sensors [1]. They present two unique functional properties that make them different from other common alloys: (i) shape memory effect (SME), which is the ability to recover the original shape after deformation; and (ii) superelasticity (SE) or (pseudoelasticity), which is the ability to recover a large non-linear strain upon loading-unloading [2,3]. Both properties occur due to a special class of non-diffusional solid state phase transformation, called thermoelastic martensitic transformation, which is a reversible transition with small volume change and low hysteresis. Within the most important SMA systems, Cu-based SMA 
plays an important role due to their large range of transformation temperatures and their flexibility, which enable the composition and processing routes tailoring, envisioning the optimization of their properties. $\mathrm{Cu}$-based SMA must present one phase at high temperature called $\beta$, that transforms into a martensite by a thermoelastic transformation, with small volume change.

These $\mathrm{Cu}$-based SMA are traditionally fabricated by casting or powder metallurgy with rigorous control of composition because a small shift from stoichiometry greatly affects their properties. Subsequent heat treatments are also commonly carried out: solution-treatments followed by quenching are used to form the martensitic phase and aging at lower temperatures is used to stabilize the martensite and memorize the shape. Because the Cu-based SMA are mostly applied in sheet or wire form, they may also undergo hot- or cold-working through forging, rolling, and extrusion. More recently, innovative processing routes have been proposed to fabricate different types of $\mathrm{Cu}$-based SMA with improved functional and/or mechanical properties. New cyclic heat treatments with low cost and less time consuming have been proposed to obtain bulk single crystals of $\mathrm{Cu}-\mathrm{Al}-\mathrm{Mn}$, which shows superior superelastic properties than in the polycrystalline form due to its polycrystal brittleness [4]. Moreover, additive manufacturing methods have also been proposed to fabricate complex shape $\mathrm{Cu}$-based SMA and the high cooling rates applied during this processing usually result in parts with higher strength and ductility [5].

Currently, Cu-based shape memory alloys are classified into several alloy systems. Traditional systems such as $\mathrm{Cu}-\mathrm{Al}-\mathrm{Zn}$ and $\mathrm{Cu}-\mathrm{Al}-\mathrm{Ni} \mathrm{SMA}$, widely studied in recent years, continue to be reported in the literature $[6,7]$; however, other systems have been drawing attention, such as $\mathrm{Cu}-\mathrm{Al}-\mathrm{Mn}$ and $\mathrm{Cu}-\mathrm{Al}-\mathrm{Be}$ SMA $[8,9]$. Furthermore, a new SMA system was recently reported in the literature, based on $\mathrm{Cu}-\mathrm{Al}-\mathrm{Fe}-\mathrm{Mn}$ [10], which shows shape memory mechanisms different from those conventionally observed. This different mechanism is related to the stressinduced martensite that can be unusually retained in the microstructure during the pre-strain condition in the superelastic regime. During heating, this retained martensitic phase rapidly transforms into austenite, and consequently, an instantaneous shape memory effect takes place. In addition to all these systems, the practice of alloying is widely used, which creates various SMA compositions. Several alloying elements can be added for the purpose of modify the properties of SMA aiming at certain specific applications. In some systems, such as for the $\mathrm{Cu}-\mathrm{Al}-\mathrm{Fe}-\mathrm{Mn} \mathrm{SMA}$, there are not many reports in the literature regarding the alloying process, and thus just a small number of alloy compositions were investigated until now. In this case, the alloy composition space for these systems is still mostly unexplored and new compositions may be discovered in the future. In contrast, for the $\mathrm{Cu}-\mathrm{Al}-\mathrm{Ni}, \mathrm{Cu}-\mathrm{Al}-\mathrm{Mn}$, and $\mathrm{Cu}-\mathrm{Al}-\mathrm{Be}$ SMA, several studies were carried out $[11,12]$, investigating the influence of different types of alloy elements on the properties of SMA. Cu-Al-Mn have currently highlighted among the $\mathrm{Cu}$-based SMA since they may present shape memory properties similar to those of NiTi alloys, but with the advantage of a lower manufacturing cost [9]. These improved properties of $\mathrm{Cu}-\mathrm{Al}-\mathrm{Mn} \mathrm{SMA}$ are directly related to the recent advancement in manufacturing processes, which allowed a more controlled alloy preparation.

Based on emerging compositions and processing routes, novel applications have been visioned for $\mathrm{Cu}$-based SMA. Elastocaloric SMA and high temperature shape memory alloys (HTSMA) are in the spotlight of Cu-based SMA studies. In this review, the authors first present the general aspects of $\mathrm{Cu}$-based SMA, following by the recent developments, where we discuss the novel processing route, new compositions, and recent applications. Lastly, we present the future perspectives and conclusions remarks.

\section{General aspects of Cu-based shape memory alloys}

\section{General features}

$\mathrm{Cu}$-based SMA are considered as an alternative to be used in high temperature applications and to other commercially available SMA in terms of their final cost, due to a lower cost of the elements, as well as a lower cost of production $[1,3]$. However, polycrystalline $\mathrm{Cu}$-based SMA are susceptible to brittle intergranular fracture, which limits their commercial application. It occurs mainly due to the high elastic anisotropy, which generates stress concentration in the grain boundaries and triple junctions due to the incompatibility of plastic and elastic deformations between the grains $[3,13,14]$.

In order to improve the mechanical properties of the polycrystalline Cu-based SMA, several efforts involving different types of processing [15-19] and modification in the compositions with the addition of alloying elements for grain refinement or precipitates formation have been carried out [20-23]. Nevertheless, the improvement in polycrystals SMA's properties to the present days have been below the researcher's expectations for them to be applied in engineering systems. The excellent shape memory properties of the $\mathrm{Cu}$-based SMA single-crystals s were only attained by the so-called oligocrystalline alloys, in which the free surface area is larger than the grain boundary areas, allowing the transformation to occur with fewer constraints [13, 14, 24-26]. As a disadvantage, the shape of the oligocrystalline alloys is generally limited to small wires or ribbons whose grains must be in a bamboo-like structure to fill the entire cross-section of the material, which limits their processing and possible applications. Another issue involving SMAs is the stabilization of martensitic-austenitic phases. It affects the shape memory properties such as transforming temperatures, hysteresis, 
strain recovery, stresses during shape recovery, among others [3]. Stabilization of the phases is thermally activated and can occur both at room temperature and higher temperatures. Both problems, intergranular fracture and stabilization of phases are highly dependent on the material processing history and the specific composition of the alloy and are related to the alloy microstructure (mainly grain size, present phases, defects, martensitic types, and variants).

\section{Shape memory effect and superelasticity in Cu-based SMA}

The shape memory behavior occurs due to a phase transformation from a high temperature phase, called austenite ( $\mathrm{A}-$ usually cubic) into a lower temperature phase with lower symmetry, called martensite ( $\mathrm{M}$-with tetragonal, orthorhombic, or monoclinic structure). In general, the austenite-martensite transformation occurs without diffusion of atoms, but rather by a shear of the crystalline lattice. This type of transformation is called "martensitic transformation" and can be irreversible, as observed in quenched mild steels, or reversible, as in SMA $[27,28]$. Regarding irreversible transformations, as occur in carbon steel and CoNi alloys, the transformation takes place during a fast cooling, forming martensites in the form of plates, laths or needles, which have immobile interfaces when applied temperature or mechanical loading [28]. In Cu-based SMA the transformation is almost completely reversible, generally called thermoelastic transformation. The main key factors for the transformation reversibility are their low hysteresis, low volume change and absence of plastic accommodation during the transformation from the austenite (also called the "parent phase"). Therefore, the martensitic microstructure is formed in a self-accommodation process, in which the variants (different orientations of martensites) are elastically accommodated inside a single preferred variant and, consequently, no macroscopic shape change is visible. This microstructure is easily modified with loading application. Thus, it is completely reversible when heated up to the austenitic field, generating a microstructure with little or no dislocations [28].

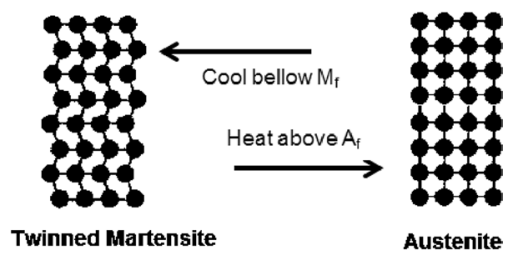

Figure 1: Scheme of the direct and reverse transformation and their final transformation temperatures.
A necessary and sufficient condition for a thermoelastic martensitic transformation is that the variants are formed without any plastic deformation by dislocation slip [29, 30]. Instead of this, they must self-accommodate $[29,30]$, normally by twinning, forming twin-related variants. When mechanically loaded, the variants detwin and orient themselves in preferential directions, forming specific variants [27]. Thus, this reversible phase transformation between austenite-martensite forms the basis for the shape memory effect and superelasticity. Some important features of thermoelastic transformation are the four temperatures at which phase transformations occur. In cooling, the direct transformation takes place, which consists in the transformation from austenite to martensite. The start transformation temperature is called $\mathrm{M}_{\mathrm{s}}$ and the end of the reaction, where $100 \%$ of the austenite has been transformed, is called $\mathrm{M}_{\mathrm{f}}$. The reverse transformation occurs upon heating, from martensite to austenite, and the start and end temperatures of this transformation are called $A_{s}$ and $A_{f}$, respectively. Between the start and end temperature range, both phases are present in the microstructure. Figure 1 illustrates the transformations and their respective temperatures. There is usually a hysteresis observed between the beginning of reverse and direct transformation $\left(\left|M_{\mathrm{s}}-A_{\mathrm{f}}\right|\right.$ or $\left.\left|A_{\mathrm{s}}-M_{\mathrm{f}}\right|\right)$ and between the start and end interval of each transformation $\left(A_{\mathrm{f}}-A_{\mathrm{s}}\right.$ or $\left.M_{\mathrm{s}}-M_{\mathrm{f}}\right)$ [31].

When stress is applied to a SMA microstructure with twinned martensite, the variants are reoriented, and part of the microstructure becomes detwinned. This process results in a macroscopic shape change of the material, which is retained when the loading is released. In this case, the mechanism of deformation is the variants reorientation in a preferred direction, which is kept after unloading. When the metal is heated above $A_{\mathrm{f}}$, the reverse transformation takes place and the martensite transforms into austenite, recovering the original shape. When cooling from this phase, the twinned martensites are formed again, without an associated change of shape, closing the SME, as shown in Fig. 2. In the detwinning process there is a minimum stress to start the process $\left(\sigma_{s}\right)$ and a stress at which it finishes completely $\left(\sigma_{\mathrm{f}}\right)$. If the material is cooled from the austenitic region at a stress above $\sigma_{s}$, the martensite formed will

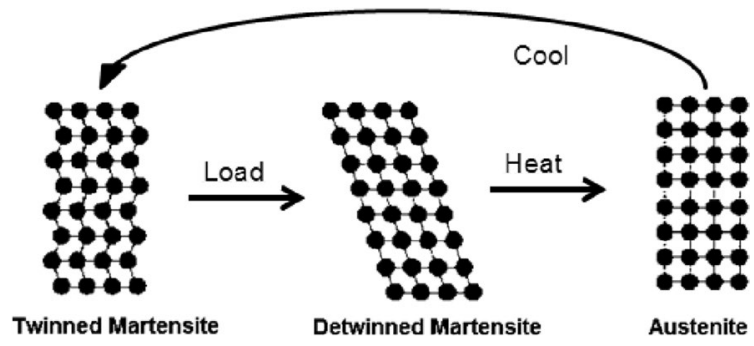

Figure 2: Illustration of the Shape Memory Effect cycle and the type of phase in each step. 


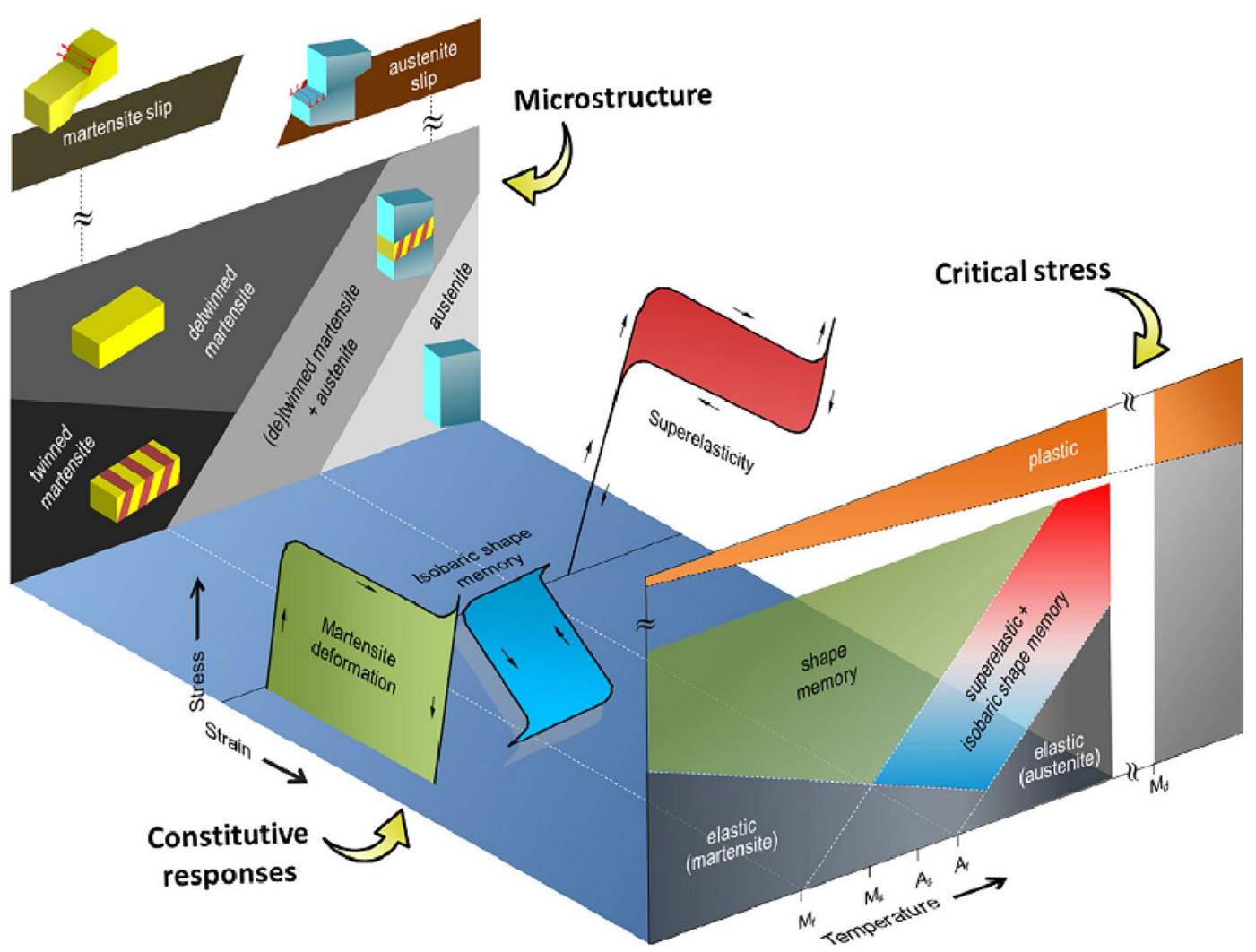

Figure 3: Scheme showing the stress-strain and temperature relationship for SMA in austenitic and martensitic phases. SME, superelasticity and dislocation slip are represented in the stress-temperature maps. Reprinted from [33]. Copyright (2017) by permission from Elsevier.

already be detwinned and there will be a change of shape with the phase transformation. With heating above $A_{\mathrm{f}}$ the shape will be recovered. It is also known that the transformation temperatures are strongly dependent on the stress applied to the material and that the higher its magnitude, the higher the transformation temperatures [1, 3, 27, 32].

Following the same principles, superelasticity is a phenomenon that happens due to the stress induced martensitic transformation within the austenitic field of the material. When the external loading is released, the martensite turns back into austenite and the deformation is recovered. Typically, a superelastcity thermomechanical path begins at a sufficiently higher temperature, i. e. above $A_{\mathrm{f}}$, at which the austenitic phase is stable. Thus, when stresses are applied, a state in which the detwinned martensite forms is reached and, when stresses are removed, the martensite is back transformed into the austenitic phase [1, $3,16,27]$. It is worth noticing that stress stabilizes the martensitic phase, increasing the transformation temperatures when applied. Figure 3 summarizes the stress-strain-temperature relationship of the SME and superelasticity in SMA and the critical stresses for plastic deformation by dislocation slip.

Within the systems of alloys that present SME and superelasticity, there are three major groups in which most shape memory alloys fit in: Cu-based SMA (Cu-Al-Ni, $\mathrm{Cu}-\mathrm{Zn}-\mathrm{Al}, \mathrm{Cu}-\mathrm{Al}-\mathrm{Mn}$, etc.), those containing NiTi intermetallic and Fe-based SMA (Fe-Mn-Si, Fi-Ni-Co-Ti, etc.). The first two groups are more commonly used in engineering applications than the latter because of their better functional properties [32]. NiTi alloys have been used for military, medical, safety and robotic applications. In the military area, they are applied in aircraft components $[1,3]$. In the field of medicine, they are applied in tweezers to remove objects through small incisions; anchors in the form of hooks to attach the tendons to the bone were used for shoulder surgery; orthodontic wires, glasses frames; guide for catheters $[32,34,35]$. In safety, they are applied as anti-scorching devices and sprinklers against fire and other types of sensors [1, 3]. Future applications foresee the use of these alloys in car engines and airplanes and electric generators that use the mechanical energy resulting from the shape transformations; springs for engine cooling systems, carburetor and engine lubrication controls [1, 32]. NiTi SMA have an excellent shape memory effect, allowing a wide range of applications from the aerospace industry to medical applications. However, they are more expensive than $\mathrm{Cu}$-based SMA, both because of the high price of the alloying elements and because of their high reactivity with oxygen at higher temperatures, which makes their processing costly. In contrast, $\mathrm{Cu}$-based SMA, besides being cheaper, have the advantage of being good thermal and electrical conductors. Besides that, 
$\mathrm{Cu}$-based SMA are the most attractive because of the higher thermal stability against aging phenomena and stabilization $[3,36]$.

One issue related to the applicability of the $\mathrm{Cu}$-based SMA is the reduced deformation recovery of the and the brittle behavior at room temperature due to intergranular fracture [3]. The main reason for this is an abnormal and high elastic anisotropy, which leads to stress concentration within the grain boundary due to elastic and plastic incompatibilities between neighboring grains, particularly when large grains are present $[3,13,14,37]$. On the other hand, Cu-based SMA thermomechanically processed showed a significant reduction of grain size to $5 \mu \mathrm{m}$, resulting in a high fracture stress and a considerable ductility in tension of $1200 \mathrm{MPa}$ and 10\%, respectively [38]. Additions of Mn and $\mathrm{Ti}$ are also known to improve ductility and control grain size in Cu-based SMA [39] and the substitution of Al for Mn improves ductility without significant changes in the transformation temperature. In $\mathrm{Cu}-\mathrm{Al}-\mathrm{Ni}$ systems, the addition of small amounts of $\mathrm{Ti}$, however, reduces grain size as a result of a decrease in the diffusion rate of the constituent atoms [3] and due to the hindering effect of $\mathrm{Ti}$-rich nanosized precipitates formed during solidification that suppresses the grain growth [39]. Elements such as $\mathrm{Zr}$ and Si also have the effect of reducing grain size [40]. The mechanical properties of these multicomponent copperbased alloys have shown promise for future applications. The Cu-13.4Al-3.1Ni-0.06Si-0.58Zr (wt\%) SMA, for example, shows tensile and deformation of fracture at around $830 \mathrm{MPa}$ and $8 \%$, respectively [40]. Cu-13.4Al-3.05Ni-0.24Ti-0.63Zr (wt\%) alloys also showed high fracture stress of $903 \mathrm{MPa}$ and a considerable fracture deformation of $8.6 \%$ in tension and the fracture mechanism changes from intergranular to transgranular [20]. Others $\mathrm{Cu}$-based systems, such as $\mathrm{Cu}-\mathrm{Al}-\mathrm{Mn}$ were developed and they have shown better ductility $[41,42]$ than others $\mathrm{Cu}$-based SMA.

In $\mathrm{Cu}$-based SMA the high temperature phase (austenite) is called $\beta$ (normally cubic at high temperatures), sometimes referred to as the mother or parent phase in martensitic transformations [43]. Different types of martensites can be formed, depending on the composition and also on the stress level of the material [3]. Generally, the martensites are named as $\gamma^{\prime}, \beta^{\prime \prime}$ and $\beta^{\prime}$. In $\mathrm{Cu}-\mathrm{Al}-\mathrm{Ni}$ and $\mathrm{Cu}-\mathrm{Al}-\mathrm{Zn}$ the phase $\beta$ becomes $\beta^{\prime}$ (monoclinic), $\gamma^{\prime}$ (orthorhombic) or a mixture $\beta^{\prime}+\gamma^{\prime}$ depending on the amount of the alloying element $[37,43,44]$. The typical morphology of the $\beta^{\prime}$ martensite is shown in Fig. 4 . The equilibrium phases that can be formed are called $\alpha$ and $\gamma$. These usually precipitate in the matrix after heat treatments, or even thermal cycles of austenite-martensite transformation. Thus, the knowledge of the precipitation temperature of these phases is important, since their presence can modify the functional properties of the alloy.

Generally, for $\mathrm{Cu}$-based SMA, before the martensitic transformation, the austenitic phase $\beta$ undergoes two types of atomic ordering during cooling: the first arrangement, B2, is among the closest neighbors and is considered unavoidable even at extremely high cooling rates [43]. The other arrangement is called $\mathrm{L} 2_{1}$ or $\mathrm{D}_{3}$, which refers to the neighboring atoms of the nearest neighbors. This can be avoided depending on the cooling rate adopted during processing. Thereby, the $\mathrm{L} 2{ }_{1}$ arrangement becomes a stabilization mechanism of the austenite and martensite phases when subjected to thermal treatments $[45,46]$. Typically, the order B2 is in the first neighbors of the central atom. When the temperature is reached for the $\mathrm{L} 2{ }_{1}$ arrangement, the outer atoms, are also ordered. There is usually a temperature range in which the ordinates $\mathrm{B} 2$ and $\mathrm{L} 2{ }_{1}$ occur. Below the ordering temperatures, the ordering phenomena take place. However, it happens since there is enough driving force for the diffusion of the atoms, considering that this is a thermally activated phenomenon. The ordering of the alloys becomes a question of great importance in the martensitic transformations, since the change of
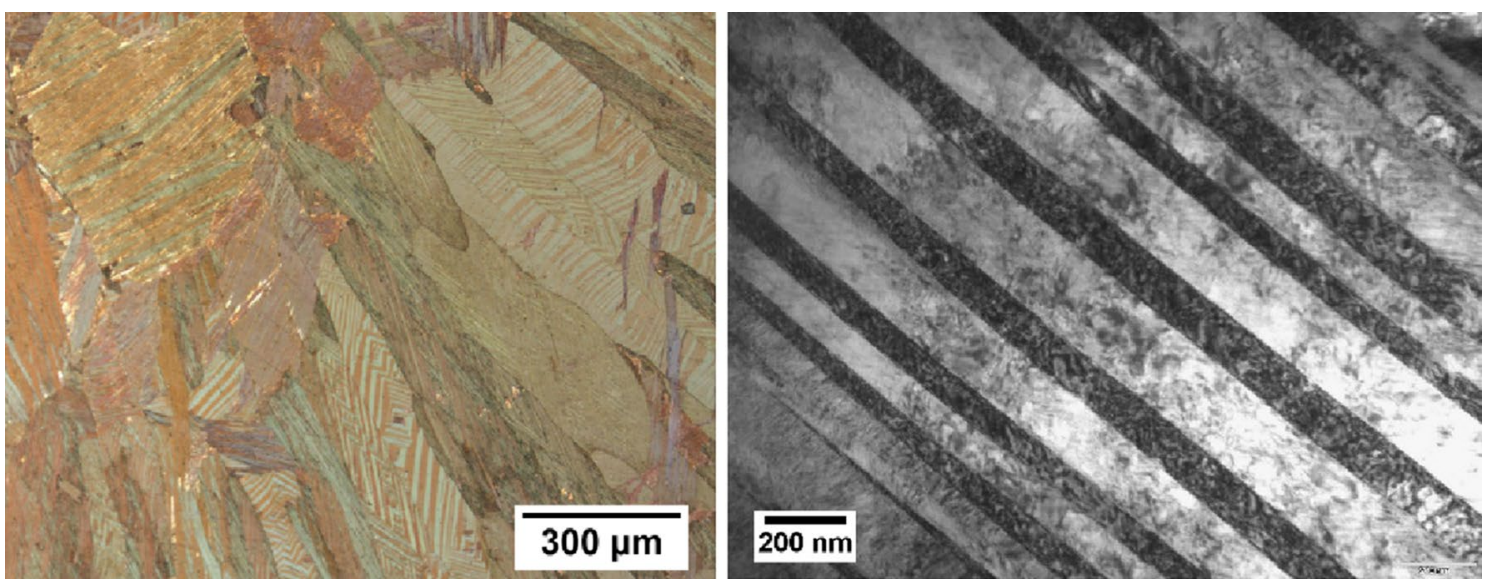

Figure 4: Typical $\beta^{\prime}$ martensitic microstructure of a $\mathrm{Cu}-\mathrm{Al}-\mathrm{Ni}$ alloy. 
the local composition and the structure of the material influences significantly the temperature range in which the phase transformation occurs [47]. Regarding the Cu-Al-Mn SMA system, similar sorting phenomena occur, since both alloying elements form solid solutions with $\mathrm{Cu}$ in the fractions used, and there is no influence of other phases [46, 48-51]

The mechanical performance of the SMA depends heavily on the microstructure of the alloy, such as the phases present and their distribution, grain size and stability of the austenite and martensite phases [47-49, 52-54]. These characteristics are derived from the history of thermomechanical processing history carried out on the material. Thus, factors linked to the functional properties of shape memory and mechanical properties will be influenced by the characteristics of the material, which will depend on the different processing parameters and treatments. Consequently, it is seen in the literature many different $\mathrm{Cu}$-based SMA(with or without the addition of a fourth alloying element) obtained by various processes reported in the review by Dasgupta [55]. One can observe a great variation in the values of fracture stress and strains, as well as grain sizes.

The deformation mechanisms for SMA, which strongly influence the mechanical properties, will depend greatly on the temperature of the material and, consequently, on the predominant phases. Thus, the mechanical properties are fully tied to the functional properties. As one of the main requirements for the reversibility of a thermoelastic martensitic transformation is the absence of slip mediated plastic deformation [33], the stress required to detwinning or reorientation $\left(\sigma_{\mathrm{dt}}\right)$ should be lower than the yield stress. This is important in order to lower the possibility of plastic deformation or plastic residual stresses in the material, which are deleterious to the SME. In view of this, along with the mechanical properties, the factors related to the functional properties such as hysteresis, transformation temperatures, damping capacity, recovery stress will be fully tied to the thermomechanical state of the material and its microstructure/composition. The thermomechanical condition affects those functional properties, by helping or impairing the phase transformation to occur. Consequently, there is a great variation in the value of these properties due to the combination of all these factors. Thus, the transformation temperatures in $\mathrm{Cu}-\mathrm{Al}-\mathrm{Ni}$ SMA can range from -200 to $200^{\circ} \mathrm{C}$ and their thermal hysteresis from 20 to $40^{\circ} \mathrm{C}$. The specific damping capacity, which takes into account the energy dissipated by the supplied energy, is between 10 and $20 \%$ [32].

\section{Recent developments of Cu-based SMA New processing routes of $\mathrm{Cu}$-based shape memory alloys (SMA)}

Some innovative processing routes have been recently proposed to process Cu-based SMA with improved functional and/or mechanical properties, exploring advanced casting methods [56, 57], powder metallurgy [57], new heat treatments[4], additive manufacturing[5], severe plastic deformation [58] or methods to obtain functionally graded materials[59].

Advanced casting methods have long been used to obtain Cu-based SMA single crystals, which show better fracture strain and larger superelasticity than polycrystalline alloys as a result of the absence of high angle grain boundaries [24]. Superelasticity up to $10 \%$ was obtained by Otsuka et al. [60] for a $\mathrm{Cu}-\mathrm{Al}-\mathrm{Ni}$ SMA fabricated by the Bridgeman method. A new and simpler method was recently proposed to obtain large single-crystal bars using cyclic heat treatment (CHT) [4]. CHT between 500 and $900{ }^{\circ} \mathrm{C}$ was applied to accelerate abnormal grain growth (AGG) in a $\mathrm{Cu}-\mathrm{Al}-\mathrm{Mn}$ SMA. Subgrains formed in association with $\alpha$-phase precipitation during the cyclic heat treatment promotes AGG, which gives rise to a single grain structure after an annealing step. As a result, excellent superelasticity up to $5 \%$ was obtained in a $15.4 \mathrm{~mm}$ diameter and $682 \mathrm{~mm}$ length $\mathrm{Cu}-\mathrm{Al}-\mathrm{Mn}$ single-crystal bar [61]. SMA single crystals of small size have also shown astonish damping behavior, with the capacity to reduce the amplitude of mechanical oscillations by the dissipation of energy. Juan et al. [62] fabricated nano- and micropillars of single crystals $\mathrm{Cu}-\mathrm{Al}-\mathrm{Ni}$ SMA by Focused Ion Beam (FIB) and they demonstrated that these pillars exhibit a damping behavior significantly better than other bulk SMA, which make them very attractive to be used in Micro-Electro-Mechanical Systems (MEMS) and other nano and microscale devices. They measured the damping capacity through multiple-cycle nanocompression tests, with the dissipated energy per cycle being represented by the hysteresis loop during the stress-strain cycle [62].

The grain boundary of Cu-based SMA has been also engineered by Ueland et al.[24]. They demonstrated that the formation of a bamboo-like oligocrystalline structure in a $\mathrm{Cu}-\mathrm{Al}-\mathrm{Ni}$ wire also shows significant improvement in fracture strain and larger superelastic strain, with intermediate values between poly- and single-crystalline structures (Fig. 5). A new direct continuous casting method was proposed to develop microfibers of Cu-based SMA with this oligocrystalline structure[56]. It was produced over meter-long microfibers, which exhibit a large superelastic strain above $8 \%$ [56].

A recently proposed method to fabricate $\mathrm{Cu}-\mathrm{Al}-\mathrm{Ni}-\mathrm{Mn}$ and $\mathrm{Cu}-\mathrm{Al}-\mathrm{Ni}-\mathrm{Mn}-\mathrm{Zr}$ SMA is spray forming $[19,63]$. The big advantage of this method is to obtain a homogeneous equiaxial microstructure, without segregation, which allows improving the mechanical properties. Near-net-shape parts with simple shapes as plates and tubes can be obtained by this method. Cava et al.[63] have shown that small addition of 0.5 at $\% \mathrm{Zr}$ changes significantly the grain size of the spray-formed $\mathrm{Cu}-\mathrm{Al}-\mathrm{Ni}$ MnSMA, decreasing the grain size from 135 to $29 \mu \mathrm{m}$. Additionally, precipitation of secondary phases during heat treatment 

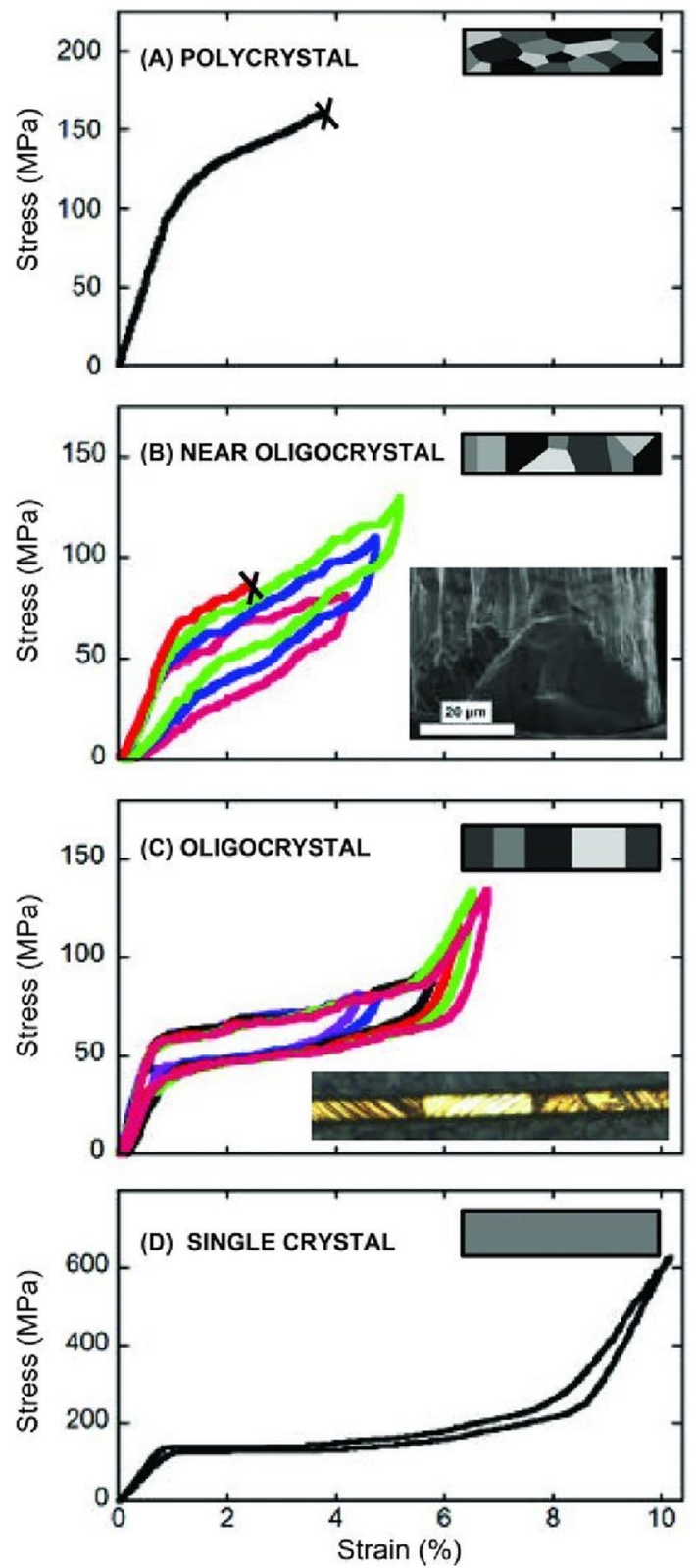

Figure 5: Stress-strain curves of a polycrystalline $\mathrm{Cu}-14.1 \mathrm{Al}-4.2 \mathrm{Ni}$, b near oligocrystalline $\mathrm{Cu}-13.7 \mathrm{Al}-5 \mathrm{Ni}$, c oligocrystalline $\mathrm{Cu}-13.7 \mathrm{Al}-5 \mathrm{Ni}$, and $\mathbf{d}$ single-crystalline $\mathrm{Cu}-14 \mathrm{Al}-4 \mathrm{Ni} .7$. The insets show the grain structure of each sample. Reprinted from Ueland et al. [24]. Copyright (2012) by permission from Wiley.

allows tuning the transformation temperature, with the martensitic start transformation temperature varying from -32 to $139{ }^{\circ} \mathrm{C}$ for isothermal heat treatments with temperature and time of $300^{\circ} \mathrm{C} / 1440 \mathrm{~min}$ and $850^{\circ} \mathrm{C} / 30 \mathrm{~min}$, respectively.

Rapid solidification techniques as melt spinning [17], $\mathrm{Cu}$ mold casting [64], and gas atomization [5, 51, 65] have also been used to produce $\mathrm{Cu}$-based SMA. These methods apply a high cooling rate, which promotes microstructural refinement and improves the mechanical properties. Nevertheless,

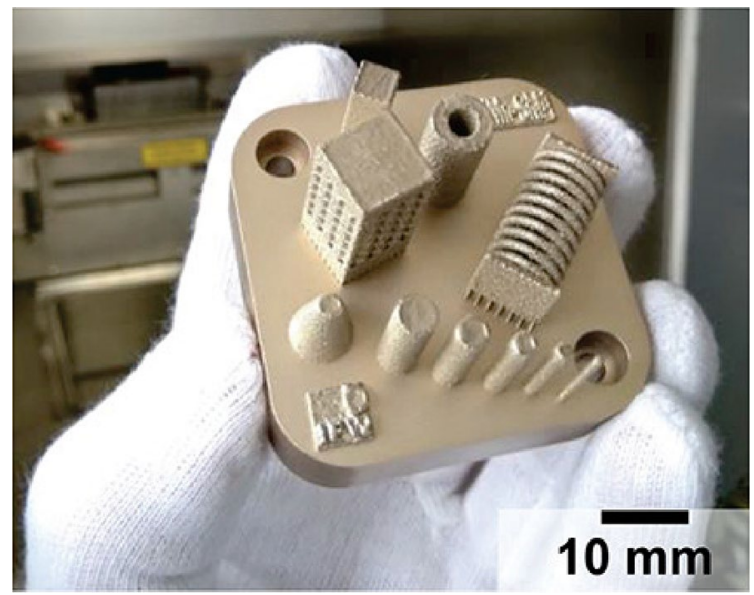

Figure 6: Image of $\mathrm{Cu}-\mathrm{Al}-\mathrm{Mn}$ samples fabricated by the additive manufacturing method of Powder Bed Fusion. Reprinted from [68]. Copyright (2021) by permission from Elsevier.

they have a limitation on the final shape and geometry that can be obtained. Laser-based additive manufacturing techniques as the Powder Bed Fusion (PBF) are also rapid solidification techniques with cooling rates varying from $10^{2}$ to $10^{5} \mathrm{~K} / \mathrm{s}$, depending on process parameters [66], which allows producing parts with complex shapes and geometries (Fig. 6). The Cu-Al-Ni-Mn [65, 67], Cu-Al-Ni-Mn-Zr [64], and $\mathrm{Cu}-\mathrm{Al}-\mathrm{Mn}$ [68] SMA have been successfully fabricated by this technique. Parts with relative density higher than $99 \%$ and with a refined columnar microstructure were obtained, with grains aligned to the build direction[67]. This promotes the formation of highly anisotropic materials, with better mechanical properties (measured uniaxially at the build direction) than samples obtained using conventional processing methods. Yield strengths comparable to cast alloys have been obtained for $\mathrm{Cu}-\mathrm{Al}-\mathrm{Ni}-\mathrm{Mn}$ and $\mathrm{Cu}-\mathrm{Al}-\mathrm{Ni}-\mathrm{Mn}-\mathrm{Zr}$ $(\approx 200 \mathrm{MPa}$ ) but with a larger ductility in tension, as a result of the greater microstructural refinement[64]. Also using atomized powders, porous scaffolds of a $\mathrm{Cu}-\mathrm{Al}-\mathrm{Ni}-\mathrm{Mn}-\mathrm{Nb}$ alloy were developed by Láper et al. [69]. The structures were produced through freeze-drying and sintering. The samples presented a porous structure of around $58 \%$ in volume, with porous size around $20 \mu \mathrm{m}$. A good damping capacity was achieved, of around $\operatorname{tg} \delta=0.05$. This parameter is commonly used to measure the damping capacity of materials. It is the ratio between the loss and storage modulus and was obtained using a dynamic mechanical analyzer (DMA).

Gustmann [70] showed that the use of a remelting step after the layers deposition during PBF can significantly improve the mechanical properties of these alloys. He also showed that a large superelasticity of up to $5 \%$ was obtained for a $\mathrm{Cu}-\mathrm{Al}-\mathrm{Ni}-\mathrm{Mn}$ using this procedure. Additionally, 
Gustmann et al.[71] showed that the remelting step can increase the relative density of $\mathrm{Cu}-11.85 \mathrm{Al}-3.2 \mathrm{Ni}-3 \mathrm{Mn}$ shapememory parts and control the grain size and transformation temperature in a broad range, depending on processing parameters. Laser surface remelting treatments have been also applied to improve the mechanical properties of a $\mathrm{Cu}$ based SMA [72]. Da Silva et al. [72] applied this treatment to $\mathrm{Cu}-\mathrm{Al}-\mathrm{Mn}-\mathrm{Ni}$ SMA plates and demonstrated an increase of up to $162 \mathrm{MPa}$ in fracture stress, $2.2 \%$ in ductility, and 20.9 $\mathrm{HV}$ in microhardness when compared with the as-cast sample.

Many recent studies have been carried out applying severe plastic deformation (SPD) to modify the microstructure/phase formation, decrease grain size and improve the functional and mechanical properties of $\mathrm{Cu}$-based shape memory alloys. López et al. [58] and Straumal et al. [73] have applied highpressure torsion (HPT) in two different $\mathrm{Cu}-\mathrm{Al}-\mathrm{Mn}$ SMA. They observed that this treatment led to diffusive transformations (precipitation of $\alpha 1$-and $\gamma 1$-phases) and promoted significant grain refinement, with grain sizes in the order of $100 \mathrm{~nm}$. These changes modified the characteristics of these alloys with a clear shift of the martensitic transformation temperatures towards higher values together with a strong transformation peak broadening. Silva Junior and Mazzer [74] showed that using appropriate parameters during HPT of a CuAlNiMn SMA, an increase in strength can be obtained without sacrifice the shape recovery ratio. Another SPD method, equal channel angular pressing (ECAP), has been applied to a $\mathrm{Cu}-\mathrm{Al}-\mathrm{Be}-\mathrm{B}$ SMA [75]. After ECAP, ultra-fine grains $(\sim 2 \mu \mathrm{m})$ were obtained but with a small fraction of martensite because of the stabilization of the austenitic phase. After heat treatment at $873 \mathrm{~K}$ and oil quenching, the grains coarsened to size up to $50 \mu \mathrm{m}$ but the fraction of martensite increases, which improved the shape memory effect.

Very recently, several processing routes have been proposed to produce functionally graded (FG) shape memory alloys[59]. Differential heat treatments, additive manufacturing methods, multi-layer thin films, powder metallurgy, and surface diffusion have been used to create FG materials. An FG SMA may transform or deform over a wide range of stress or temperature, which can be interesting especially in actuating and sensing applications to improve the actuators and sensors controllability. The FG SMA can be obtained by microstructural, compositional, or geometrical gradients (Fig. 7) but these concepts have been applied only to TiNi-based SMA so far[59].

\section{Novel Cu-based SMA compositions}

Until recently, most of the studied Cu-based SMA were classified in two main systems: $\mathrm{Cu}-\mathrm{Al}-\mathrm{Ni}$ and $\mathrm{Cu}-\mathrm{Zn}-\mathrm{Al}$ [55]. The former system has better thermal and microstructure stability and greater potential for high-temperature applications, while the second has a lower production cost and lower transformation

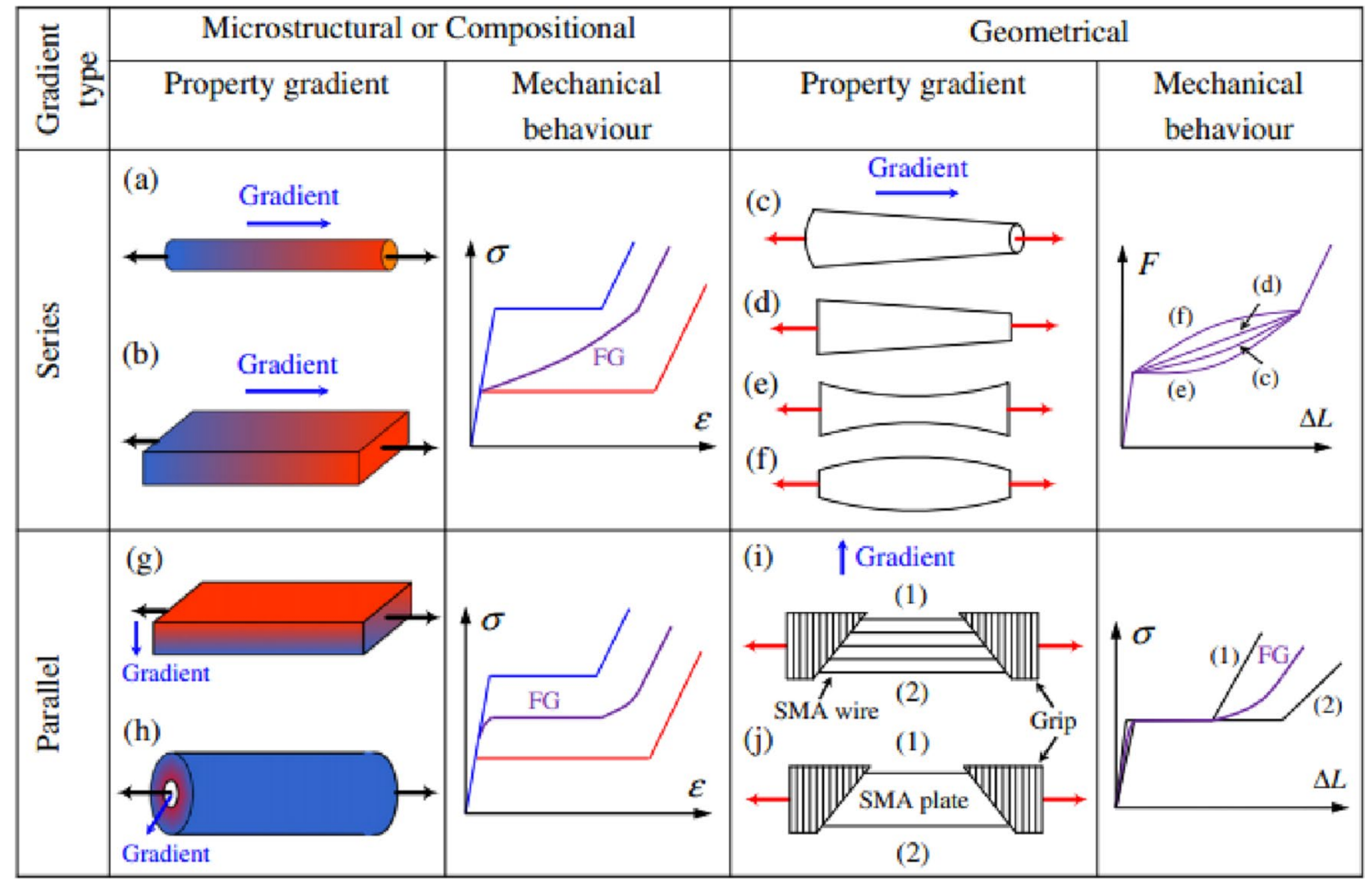

Figure 7: Designs of functionally graded (FG) NiTi-based SMA by microstructure or composition and geometrical gradient type and their corresponding mechanical behaviors. Reprinted from Shariat et al. [59]. Copyright (2017) by permission from Elsevier. 
temperatures. These $\mathrm{Cu}-\mathrm{SMA}$ systems exhibit low ductility due to the strong tendency to intergranular fracture, which is attributed to the formation of a highly ordered structure and elastic anisotropy. This brittle behavior hinders the mechanical processing of these alloys, making it difficult even to shape them into sheets and wire, which is important for stents and guidewires applications $[3,39]$.

In this context, new alloys have been developed aiming to overcome these issues. New compositions are suggested in the literature based on the systems previously presented, but not limited to them. Most of these new compositions are obtained based on ternary or quaternary alloying, which corresponds to one of the most employed methods to improve the properties of the Cu-based SMA. Several alloying elements are recommended in the literature and the influence of each specific alloying element will be addressed in the sequence for different $\mathrm{Cu}$-based SMA systems.

The addition of $\mathrm{Mn}$ to $\mathrm{Cu}-\mathrm{Al}-\mathrm{Ni}$ SMA for example has substantially improved the ductility of these alloys without significantly modifying the martensitic transformation temperatures. The replacement of about $2 \%$ of $\mathrm{Al}$ by $\mathrm{Mn}$ lead to a suppression of the eutectoid reaction $\beta_{1} \rightarrow \alpha+\gamma_{2}$ [76], favoring the stabilization of the martensitic phase and decreasing the effect of intergranular embrittlement. Furthermore, for $\mathrm{Cu}-\mathrm{Al}-\mathrm{Ni}-\mathrm{Mn} \mathrm{SMA}$, additions of a fifth alloying element have been proposed, such as $\mathrm{Nb}[7,77]$. Small additions of $\mathrm{Nb}$, of about $0.5 \mathrm{wt} \%$, in the $\mathrm{Cu}-11.45 \mathrm{Al}-3.2 \mathrm{Ni}-3 \mathrm{Mn}$ (wt\%) SMA, resulted in a maximum shape recovery of $1 \%$ when subjected to stresses of $690 \mathrm{MPa}$, thus presenting a recovery ratio of $73 \%$. In addition, the fracture stress for this SMA with $\mathrm{Nb}$ additions was about $1560 \mathrm{MPa}$. Another alloying element reported in the $\mathrm{Cu}-\mathrm{Al}-\mathrm{Ni}-\mathrm{Mn}$ quaternary system is $\mathrm{Zr}$ [78, 79]. An addition of $0.5 \mathrm{wt} \%$ of $\mathrm{Zr}$ was proposed, which leads to an increase in the martensitic transformation temperatures. Upon annealing, precipitation of the $\mathrm{Y}$-phase $\left(\mathrm{Cu}_{2} \mathrm{AlZr}\right)$ in the grain boundaries was observed. These precipitates hamper grain growth and seem to produce an irregular phase transformation on heating [78]. Cu-11.35Al-3.2Ni-3Mn-0.5Zr (wt\%) SMA processed by different routes presented a maximum tensile strength between 500 and $600 \mathrm{MPa}$ and a fracture deformation between 5.4 and $7.2 \%$. Under compression, fracture stress and strain of up $1200 \mathrm{MPa}$ and $19.7 \%$ were obtained.

Low solubility quaternary elements play an important role in inhibiting grain growth and improving mechanical properties for $\mathrm{Cu}$-based SMA. For instance, Boron is recognized as a refiner element that produces a significant improvement in mechanical properties $[80,81]$. A more recent study investigated the doping of $\mathrm{B}$ in the $\mathrm{Cu}-12 \mathrm{Al}-4 \mathrm{Ni}$ (wt\%) SMA [41]. It was reported that the addition of boron in small amounts resulted in an increase in ductility of more than four times compared to the base alloy. Besides that, shape recovery was considerably increased with the addition of $0.3 \mathrm{wt} \% \mathrm{~B}$, from $75 \%$ (base alloy) to $95 \%$. An increase in martensitic transformation temperatures was also reported with the doping of $\mathrm{B}$.

Saud et al. [76] reported the addition of $\mathrm{Co}$ in the $\mathrm{Cu}$ 11.9Al-4Ni (wt\%) SMA and observed the formation of a new $\gamma_{2}$-phase. The size and volume fraction of $\gamma_{2}$-phase increases as more Co is added to the alloy. The presence of the $\gamma_{2}$-phase resulted in an increase in the transformation temperatures compared to the unmodified alloy. Furthermore, the addition of $1 \mathrm{wt}$ \% Co resulted in a maximum ductility of $7 \%$ and an increase in recovered deformation by the shape memory effect. Titanium addition in the $\mathrm{Cu}-\mathrm{Al}-\mathrm{Ni}$ SMA system has also been reported $[82,83]$. Similarly, as observed for Co, a new phase has been indexed with $\mathrm{Ti}$ additions, which is denoted as $\mathrm{X}$-phase $\left.(\mathrm{Cu}, \mathrm{Ni})_{2} \mathrm{AlTi}\right)$. With Ti additions, a sharp refinement of the grain size of about $70 \%$, an increase in ductility from 1.65 to $3.2 \%$, and an increase in the recovered deformation by the shape memory effect were obtained. Optimized properties, i.e. better mechanical properties and higher transformation temperatures were obtained for additions of $0.7 \mathrm{wt} \% \mathrm{Ti}$.

The addition of Ag nanoparticles has also been suggested in the literature [84]. The addition of $0.25 \mathrm{wt} \% \mathrm{Ag}$ nanoparticles results in a microstructural modification with the formation of precipitates enriched in Ag. The volume fraction of the $\gamma_{1}^{\prime}$-phase is reduced and the morphology of the $\beta_{1}^{\prime}$-phase is refined with the addition of Ag nanoparticles. In addition, fracture strength and ductility were improved with the addition of Ag nanoparticles: values up to $420 \mathrm{MPa}$ and $2.35 \%$ wereobtained respectively. Furthermore, the presence of $\mathrm{Ag}$ in these alloys increased the shape recovery ratio from 50 to $80 \%$. The presence of this noble element also provided an improvement in corrosion resistance due to the formation of a surface protective layer of complex stoichiometry.

The addition of rare earth to $\mathrm{Cu}-\mathrm{Al}-\mathrm{Ni}$ alloys has also been reported recently [85]. The addition of $\mathrm{Nd}$ was performed to the $\mathrm{Cu}-13 \mathrm{Al}-4 \mathrm{Ni}$ (wt\%) SMA and the grain size was reduced from the millimeter scale to a few hundred microns. The addition of $\mathrm{Nd}$ did not alter the phase formation for this SMA, which for this composition is composed of the $\beta^{\prime}$ and $\gamma^{\prime}$ martensitic phases. However, a second phase $(\mathrm{Al}, \mathrm{Ni}) \mathrm{Cu}_{4} \mathrm{Nd}$, with a hexagonal structure, can be formed if the $\mathrm{Nd}$ content is increased. For $\mathrm{Nd}$ contents of $0.5 \mathrm{wt} \%$, an increase in fracture stress and ductility was obtained, from $580 \mathrm{MPa}$ and $10.5 \%$ (base alloy) to $940 \mathrm{MPa}$ and $18.3 \%$, respectively. The presence of $\mathrm{Nd}$ also culminated in an increase in the superelasticity, with a reversible strain value of $6.8 \%$ being obtained for an $\mathrm{Nd}$ content of $0.2 \mathrm{wt} \%$ under the condition of pre-strain of $10 \%$ after heating. Additions of other rare earth elements were also reported in the literature, such as $\mathrm{Gd}$, in which there was also high grain refining and improved mechanical properties [86]. 
Other several additions of elements were reported in the literature, such as $\mathrm{Cu}-\mathrm{Al}-\mathrm{Ni}-\mathrm{Hf}$ [6], $\mathrm{Cu}-\mathrm{Al}-\mathrm{Ni}-\mathrm{Ta}$ [87], $\mathrm{Cu}-\mathrm{Al}-\mathrm{Ni}-\mathrm{Fe}[88,89], \mathrm{Cu}-\mathrm{Al}-\mathrm{Ni}-\mathrm{Zn}$ [11], $\mathrm{Cu}-\mathrm{Al}-\mathrm{Ni}-\mathrm{Cr}$ [90], $\mathrm{Cu}-\mathrm{Al}-\mathrm{Ni}-\mathrm{Ti}-\mathrm{Cr}$ [91], $\mathrm{Cu}-\mathrm{Al}-\mathrm{Ni}-\mathrm{V}$ [92] and $\mathrm{Cu}-\mathrm{Al}-\mathrm{Ni}-\mathrm{Sn}$ [93].

More recently, the $\mathrm{Cu}-\mathrm{Al}-\mathrm{Mn}$ SMA system, which was first reported in 1995 by Kainuma et al. [9, 94], has been receiving great attention in the literature. This is attributed to the recent development of metal alloy manufacturing processes that allow the production of these SMAs with adequate control of texture and grain size, enabling the achievement of superior superelastic properties than those of traditional $\mathrm{Cu}-\mathrm{Al}-\mathrm{Ni}$ and $\mathrm{Cu}-\mathrm{Al}-\mathrm{Zn}$ SMA systems $[9,61,95]$. Cu-Al-Mn SMA generally have an $\mathrm{Al}$ content of less than 18 at\% and show excellent ductility and good shape memory effect mainly due to the low degree of ordering of their $L 2_{1}$ parent phase $[9,68,94]$. The low-temperature martensitic phases that can be found in these alloys are: $\alpha_{1}^{\prime}$ (3R) observed for low $\mathrm{Al}$ contents, $\beta_{1}^{\prime}(18 \mathrm{R})$ for intermediate $\mathrm{Al}$ contents, and $\gamma_{1}^{\prime}(2 \mathrm{H})$ that is predominant in alloys with high $\mathrm{Al}$ contents [96]. Alloys of this system with $\mathrm{Al}$ content lower than 14 at $\%$ show two distinct austenitic phases: $\beta$ (A2, disordered) and $\beta_{1}$ (L2 ${ }_{1}$, ordered). Alloys with Al content between 16 and 17 at $\% \mathrm{Al}$ only have the $\beta_{1}$-phase, which results in improved shape memory properties [96]. This Al compositional range is generally used for the manufacture of the $\mathrm{Cu}-\mathrm{Al}-\mathrm{Mn}$ SMA.

The degree of ordering of $\mathrm{Cu}-\mathrm{Al}-\mathrm{Mn}$ SMA tends to decrease with the reduction of $\mathrm{Al}$ content, and because of this disorder, there is an increase in both ductility and cold workability for these alloys. As an example, it is possible to obtain tensile elongation values greater than $10 \%$ and cold workability greater than $60 \%$, which corresponds to values higher than that found for the alloys of the $\mathrm{Cu}-\mathrm{Al}-\mathrm{Zn}$ and $\mathrm{Cu}-\mathrm{Al}-\mathrm{Ni}$ systems. Combined with the improved mechanical properties, $\mathrm{Cu}-\mathrm{Al}-\mathrm{Mn}$ can present shape memory properties similar to those reported for NiTi alloys. Superelasticity values of $7.5 \%$ have been reported for these alloys, which are slightly below those obtained for NiTi-based alloys ( 8\%) [97]. Superelasticity can be improved both by controlling grain size, where the increase in grain size generates an increase in superelasticity, as well as by texture introduction. Texture development is mainly achieved by thermomechanical deformation processes. Since the alloys of the $\mathrm{Cu}-\mathrm{Al}-\mathrm{Ni}$ and $\mathrm{Cu}-\mathrm{Al}-\mathrm{Zn}$ systems have low cold workability, the texture introduction during processing is quite difficult. In contrast, $\mathrm{Cu}-\mathrm{Al}-\mathrm{Mn} \mathrm{SMA}$, with higher ductility can be mechanically cold processed, and thus texture may be implemented in these alloys. The possibility of processing by cold deformation allows the development of low-cost SMA with shapes that would only be possible through special processing such as additive manufacturing [97]. These alloys can be cold deformed by several processes that include rolling, punching, and cutting. Applications of the $\mathrm{Cu}-\mathrm{Al}-\mathrm{Mn}$ SMA have been reported, as in the biomedical field where a small device in the shape of a plate of few centimeters long is used to relieve ingrown nails using the shape memory effect $[97,98]$.

Researches have also been directed towards the development of alloys of the $\mathrm{Cu}-\mathrm{Al}-\mathrm{Mn}$ system with a smaller volumetric fraction of grain boundaries since the superelasticity is drastically increased with their reduction [97]. Great effort has been made to manufacture large-scale single-crystalline parts of $\mathrm{Cu}-\mathrm{Al}-\mathrm{Mn} \mathrm{SMA}$, which can be implemented in the civil engineering and architecture field.

$\mathrm{Cu}-\mathrm{Al}-\mathrm{Mn}$ has also been studied aiming improvement of other typical properties of SMA, such as its high damping capacity. This property is very important for applications where vibration and noise attenuation of engineering structures is required. Due to their thermoelastic properties, SMA are excellent candidates for this type of application as they have a high damping capacity due to the movement of interfaces during the martensitic transformation [99]. The damping capacity of structures can be usually improved by introducing pores during processing. Recent studies [100] have reported the fabrication of $\mathrm{Cu}-11.9 \mathrm{Al}-2.5 \mathrm{Mn}$ (wt\%) SMA with an interconnected pore structure to obtain a high damping capacity since porosity acts as energy scattering centers.

Also aiming to improve the damping properties, $\mathrm{Cu}-\mathrm{Al}-\mathrm{Mn}$ /polystyrene composites were manufactured via sintering-dissolution and sol-gel methods. Porous alloys, which already had excellent compressive energy absorption and damping properties, had their properties improved when prepared in a composite form. This is attributed to the impediment effect on the pore collapse by polystyrene and the overlapping of multiple sources of damping.

Alloying can also be used to improve the properties of the $\mathrm{Cu}-\mathrm{Al}-\mathrm{Mn}$ SMA. Several distinct elements have been investigated in the literature. Sampath et al. [12] reported the addition of boron and observed an effective grain refining of about $80 \%$, with a consequent increase in phase transformation temperatures. Enhanced grain refinement was also obtained using CuZr inoculants in an amount of $0.9 \mathrm{wt} \%$ [101]. The use of these inoculants resulted in a reduction in grain size to $37 \mu \mathrm{m}$ from an initial grain size of $1050 \mu \mathrm{m}$. This grain size reduction increased mechanical strength and elongation, which were attributed to the higher grain boundaries volumetric fraction that hinder dislocations movement. Recent studies show that inoculation using rare earth increases the ductility of the $\mathrm{Cu}-\mathrm{Al}-\mathrm{Mn}$ SMA and may avoid intergranular failure. Lu et al. [102] studied Ce doping and obtained an increase in both ductility, mechanical strength, and damping capacity. Other compositions that can be found in the literature for the $\mathrm{Cu}-\mathrm{Al}-\mathrm{Mn}$ system are those with the addition of $\mathrm{Ag}$ and $\mathrm{Nb}$ [103].

Another recently reported SMA system is the one based on the $\mathrm{Cu}-\mathrm{Al}-\mathrm{Fe}-\mathrm{Mn}$, whose composition range is $\mathrm{Cu}-(12.2-12.9)$ 
Al-(3.8-4.3)Fe-(5.5-6.6)Mn (wt\%) [10]. These alloys show an instantaneous shape memory effect during heating, which results from a recovery mechanism slightly different from that usually reported for conventional SMA. This mechanism consists of the recovery of the $2 \mathrm{H}$ martensitic phase $\left(\gamma_{1}^{\prime \prime}\right)$ that was previously stabilized during the pre-strain condition. During the deformation of the sample in the superelastic regime, above the temperature $A_{\mathrm{f}}$ (austenitic transformation final temperature), the martensitic phase is stress-induced from the parent phase $\left(L 2_{1}\right)$. With load removal, the martensitic phase is stabilized in a metastable condition since the temperatures are significantly above $M_{\mathrm{s}}$ (martensitic transformation start temperature). During sample heating, this retained martensitic phase instantly transforms into the parent phase, and consequently, the sample immediately recovers its shape. These alloys are considered to be highly temperature-sensitive, with a low hysteresis during shape recovery $\left(\sim 25^{\circ} \mathrm{C}\right)$, which results in an instantaneous recovery speed. In this way, the shape recovery process can be completed instantly, accompanied by an unusual "jump" of the sample. This high-temperature sensitivity can be used for high-performance sensor applications. Furthermore, these new SMA present a shape recovery of about $9 \%$ that corresponds to a relatively high value for $\mathrm{Cu}$-based SMA.

New $\mathrm{Cu}-\mathrm{Al}-\mathrm{Fe}-\mathrm{Mn}$ SMA has been recently suggested in the literature with the addition of a fifth element with low solubility in $\mathrm{Cu}$, such as $\mathrm{Nb}$ and $\mathrm{Zr}$ [104]. Due to their low solubility, these alloying elements, when present, tend to form second phases that can assist the martensite stabilization after unloading. The addition of these elements produces a microstructure at room temperature consisting of the parent phase $\mathrm{L} 2_{1}-\mathrm{Cu}_{2} \mathrm{AlMn}$, small fractions of the $2 \mathrm{H}$ martensitic phase, and fine second $\beta$-phases ((Fe, $\mathrm{Al}, \mathrm{Zr})$ or $(\mathrm{Fe}, \mathrm{Al}, \mathrm{Nb}))$. The fraction of the $\beta$ phase increases with the addition of $\mathrm{Zr}$ or $\mathrm{Nb}$. Again, $2 \mathrm{H}$ martensite is stabilized during the pre-strain condition, in this case even for deformations smaller than $6 \%$. Stabilization of the martensitic phase is attributed to the inhibition of the movement of the habit planes during unloading due to the presence of precipitates and dislocations in the microstructure. This stabilization can be reversed on heating through the shape memory effect (SME). The maximum SME value obtained was $4.4 \%$ for $\mathrm{Nb}$ and $\mathrm{Zr}$ contents of $1 \%$ and $2 \%$, respectively. More recent studies related to the $\mathrm{Cu}-\mathrm{Al}-\mathrm{Fe}-\mathrm{Mn}$ system can be found in the literature [105-107].

Another system of $\mathrm{Cu}$-based SMA is $\mathrm{Cu}-\mathrm{Al}-\mathrm{Be}$, which was discovered in 1982. Despite not being a recent $\mathrm{Cu}$-based SMA system, there has been a growing number of recent works about new compositions [8]. $\mathrm{Cu}-\mathrm{Al}-\mathrm{Be}$ consists of a family of $\mathrm{Cu}$-based SMA with compositions close to the eutectoid point which has good thermal stability. These SMA present, in addition to shape memory and superelasticity effects, other interesting properties, such as good corrosion resistance and good mechanical strength. There is a particular technological interest for these SMA for applications at low and intermediate temperatures. The addition of small amounts of Be drastically reduces the phase transformation temperatures, thus allowing superelasticity to occur at very low temperatures. Some empirical equations have been proposed to determine the martensitic transformation temperatures in $\mathrm{Cu}-\mathrm{Al}-\mathrm{Be}$ alloys based on their composition $[10,108]$. Hence, these alloys can be used in a wide range of temperatures and can even be considered for cryogenic applications.

Recently studies have been carried out to modify the properties and characteristics of these SMA by alloying. Narasimha et al. [109] studied the addition of $\mathrm{Zr}$ in the $\mathrm{Cu}-11.42 \mathrm{Al}-0.45 \mathrm{Be}$ alloy (wt\%) and observed a reduction in grain size of $89 \%$, with a consequent increase in ductility and mechanical strength. Furthermore, the addition of up to $0.3 \mathrm{wt} \% \mathrm{Zr}$ did not change the shape recovery ratio, despite an increase in martensitic transformation temperatures. Melo et al. $[110,111]$ produced $\mathrm{Cu}-\mathrm{Al}-\mathrm{Be}$ SMA with additions of $\mathrm{Ni}$ and $\mathrm{Nb}$ and observed a large reduction in grain size, as well as an increase in mechanical strength and ductility. Candido et al. [112] studied the addition of $\mathrm{Cr}$ in the $\mathrm{Cu}-\mathrm{Al}-\mathrm{Be}$ system and also observed a marked reduction in grain size. Additions of $0.2 \mathrm{wt} \% \mathrm{Cr}$ led to higher mechanical strengths and to lower martensitic transformation temperatures, allowing the application of these alloys at even lower temperatures Rare earth elements such as gadolinium have also been added to these SMA at low levels between 0.05 and $0.15 \mathrm{wt} \%$. Again, large grain refinement was obtained, from $463 \mu \mathrm{m}$ in the Gd-free condition to $81 \mu \mathrm{m}$, which corresponds to a reduction in grain size of about $82 \%$. Mechanical strength and ductility were increased with the addition of $0.08 \mathrm{wt} \%$ $\mathrm{Gd}$. However, a reduction of the shape recovery ratio from 97 to $65 \%$ was also observed.

More recently, boron doping in $\mathrm{Cu}-\mathrm{Al}-\mathrm{Be} \mathrm{SMA}$ has been proposed [113]. Boron doping is also used for the refining of $\mathrm{Cu}-\mathrm{Al}-\mathrm{Mn} \mathrm{SMA}$, as previously discussed. The addition of $0.15 \mathrm{wt} \% \mathrm{~B}$ in the $\mathrm{Cu}-11.5 \mathrm{Al}-0.57 \mathrm{Be}$ SMA produced an increase in the ultimate tensile strength to $744 \mathrm{MPa}$ and an increase in ductility to $29 \%$. Besides that, fracture morphology changed from intergranular to transgranular with B doping. A maximum superelasticity of $4 \%$ was obtained by B doping, which is well suited to use as dampers in seismic applications.

The addition of alloying elements to the $\mathrm{Cu}-\mathrm{Al}-\mathrm{Be}$ SMA must be carried out with caution since large concentrations of added elements can exceed the solubility limit and generate the precipitation of second phases, which modify the shape memory effects [114]. With the formation of precipitates, the fraction of $\mathrm{Be}$ and $\mathrm{Al}$ in the $\beta$-phase matrix is probably reduced, which alters the martensitic transformation temperatures that are strongly dependent on the chemical composition, mainly on Be content [114]. Variations of about $0.1 \mathrm{wt} \% \mathrm{Be}$ can result in a modification of about $90^{\circ} \mathrm{C}$ [115].

The most important properties (transformation temperatures range, recovery strain, superelasticity, fracture strain, and stress, 


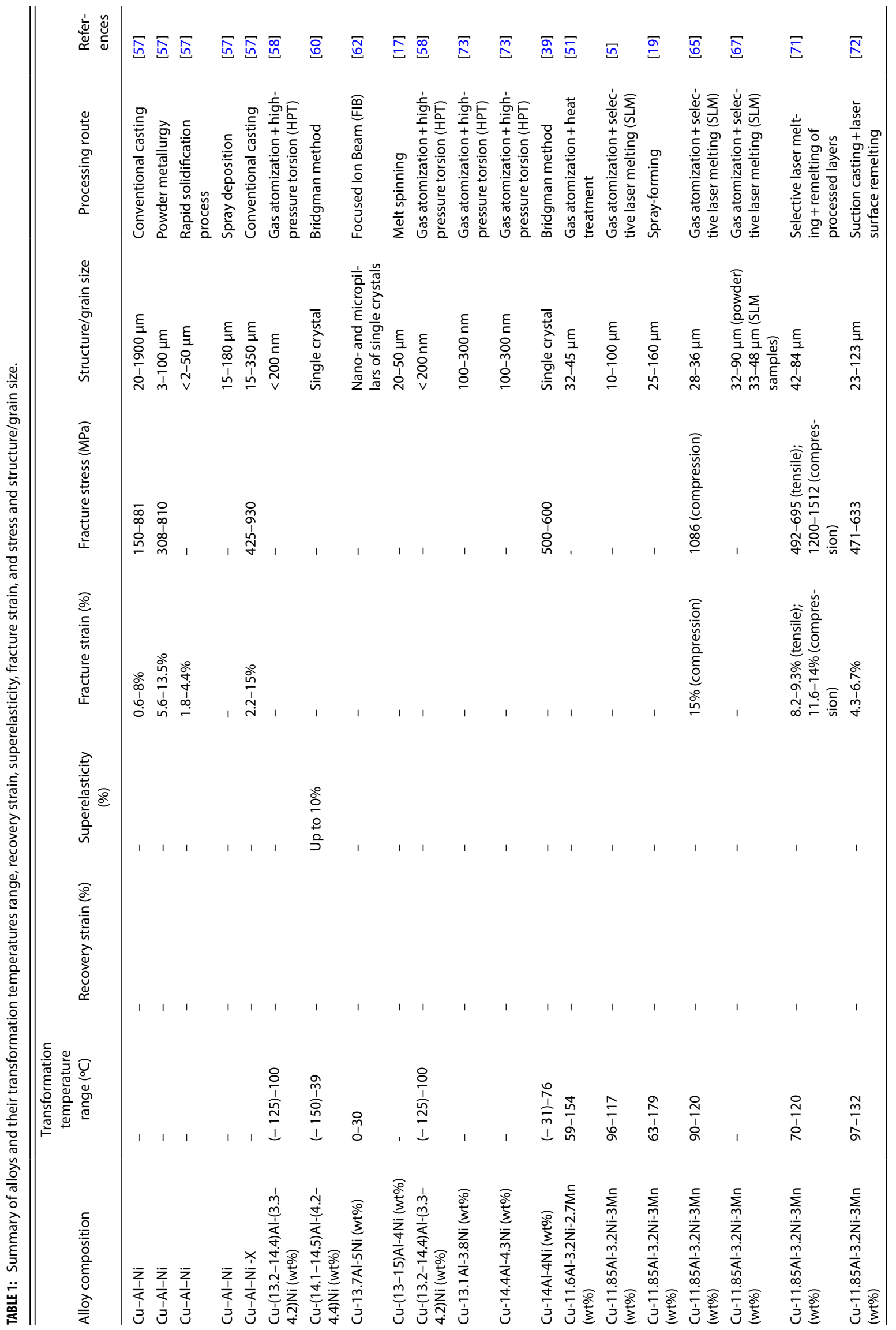




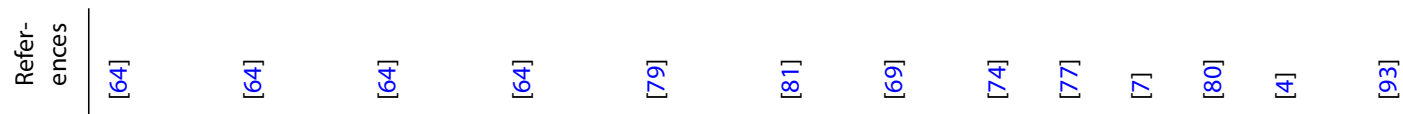

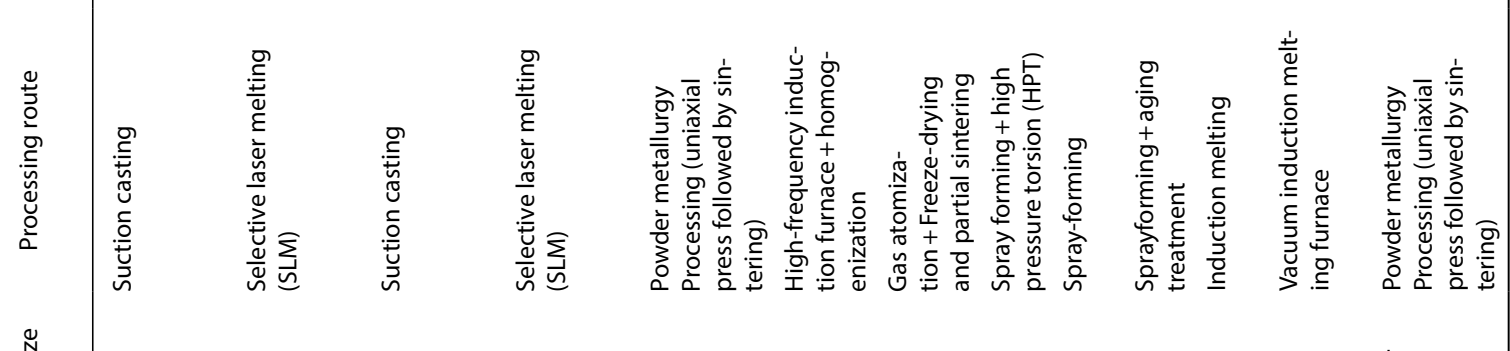

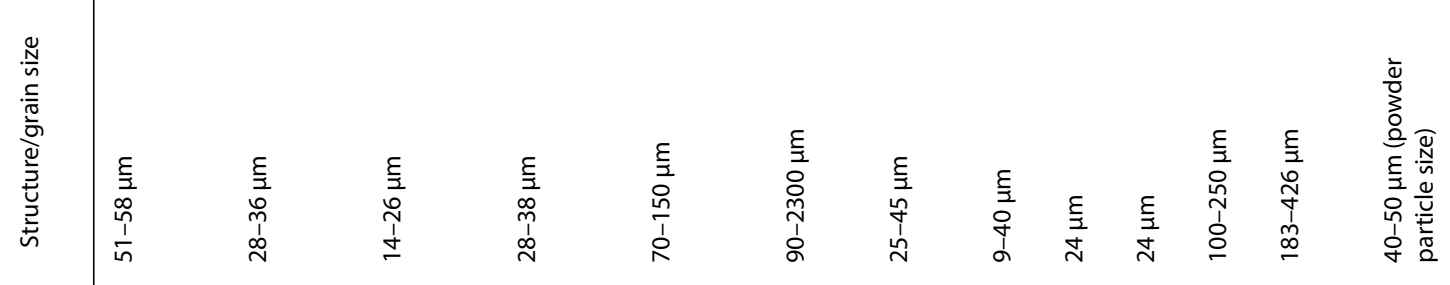

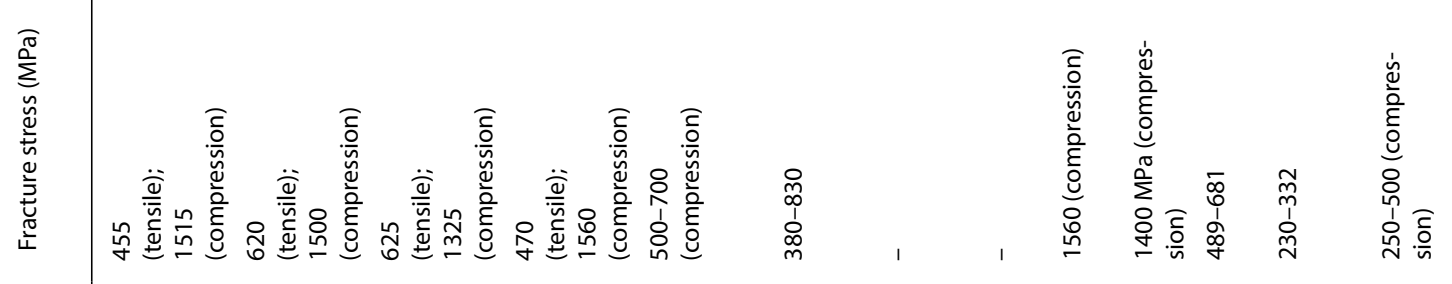

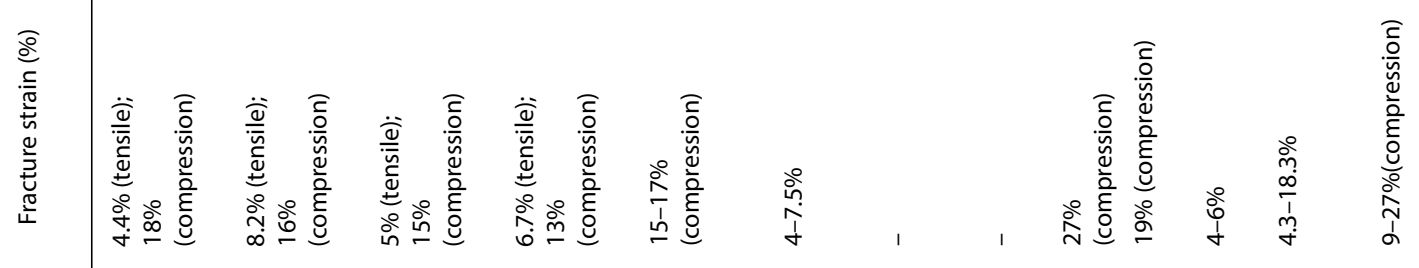

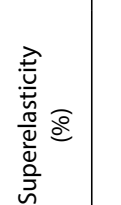

$\frac{\sqrt{9}}{5}$

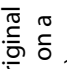

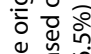

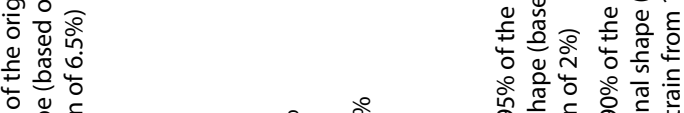

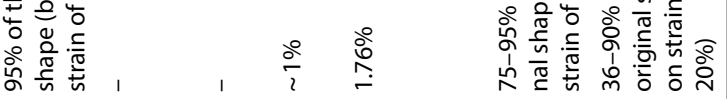

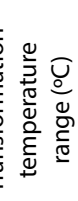

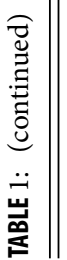

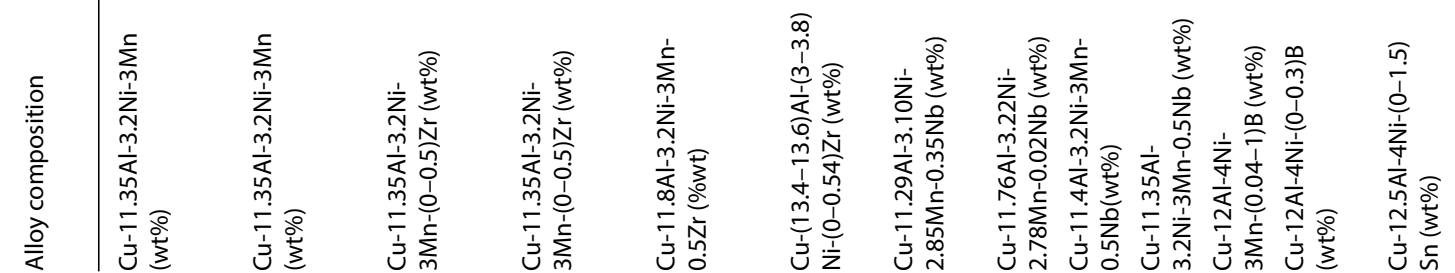




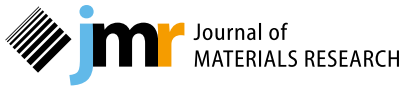

Invited Feature Paper-Review

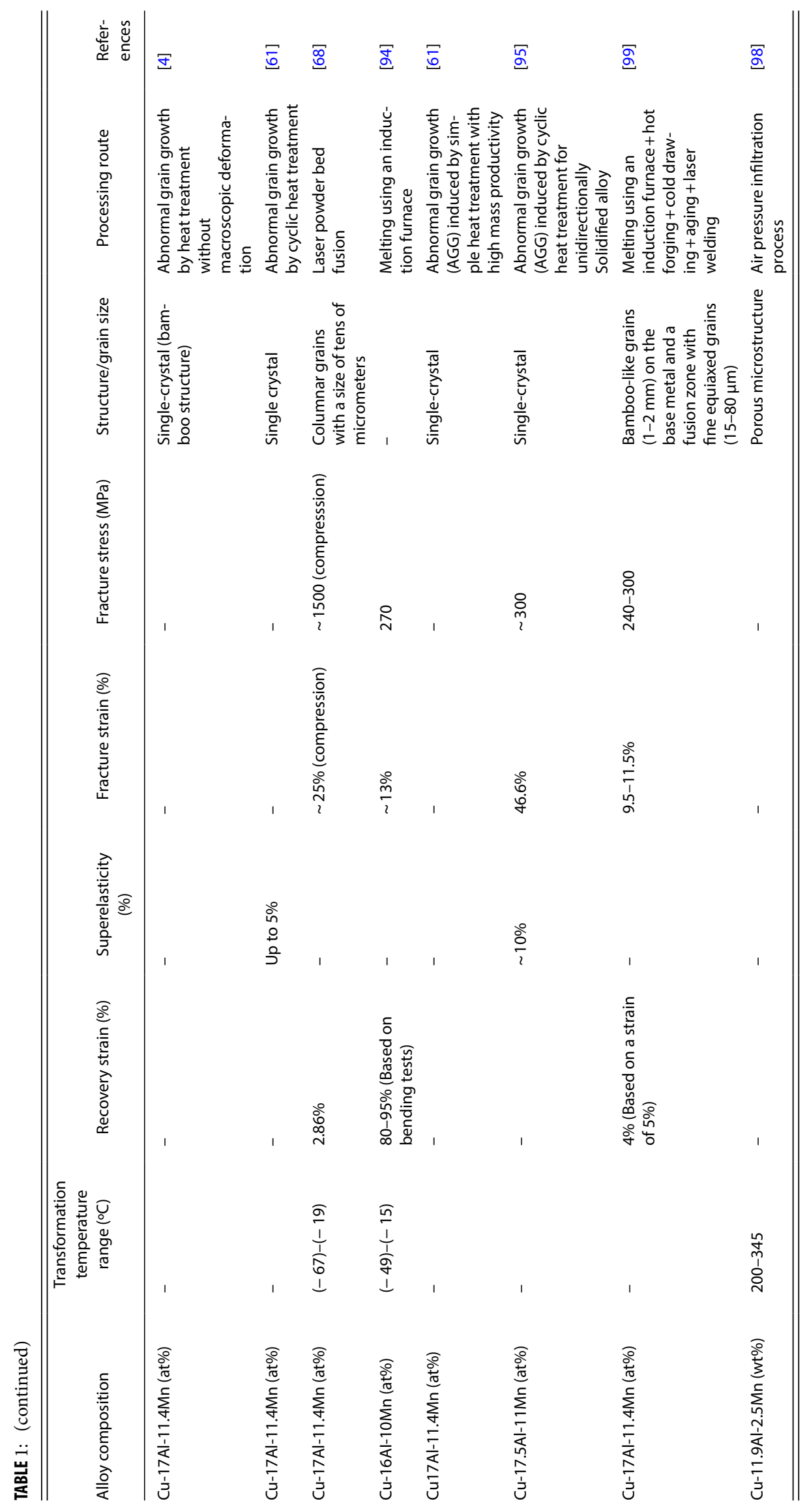

(c) The Author(s) 2021

175 
structure/grain size) and processing routes for the alloys discussed in this manuscript are summarized in Table 1

\section{Recent applications}

Besides the well known SMA applications, Cu-based shape memory alloys have been attracting attentions due to the possibility of applying them at higher temperatures than others SMA systems. Moreover, the use of their phase transformation energies makes possible the application in energy/heat harvesting materials, such as elastocaloric alloys. The next sections will be dedicated to discussing these topics.

\section{Elastocaloric effect (eC): The promising $\mathrm{Cu}-\mathrm{Zn}-\mathrm{Al}$ and $\mathrm{Cu}-\mathrm{Al}-\mathrm{Mn}$ systems}

One recent important application of $\mathrm{Cu}$-based SMA is related to solid-state cooling by the elastocaloric effect $(\mathrm{eC})$, exploiting the latent heat $(\Delta \mathrm{H})$ absorbed from the superelastic phase transformation. As well known for first order transformation, the martensitic reverse transformation in thermoelastic SMA releases heat during the direct transformation (exothermic phase transformation from austenite to martensite) and absorbs heat during the reverse transformation (endothermic phase transformation from martensite to austenite). The elastocaloric cycle consists of loading and unloading a SMA in the superelastic region, as shown in Fig. 8. As a first-order phase transformation from a high-symmetry phase (austenite) to a low-symmetry phase (martensite), the entropy change involves the release or absorption of heat. This change in entropy could result in vaiation of temperature, which allows cooling around $10 \mathrm{~K}$ for $\mathrm{Cu}$-based alloys [116], as will be further detailed in the next sections. The coefficient of performance (COP) is ratio between the absorbed energy $\Delta \mathrm{H}$ and the energy spent in the elastocaloric cycle and is considered an indicator for $\mathrm{eC}$ in SMA. For certain alloys, the eC efficiency is comparable to the Carnot process in the same thermal operation [117].
Generally, the four steps elastocaloric cycle consists firstly in the mechanical loading of the alloy, which induces the direct martensitic transformation. Heat is released by the material while the transformation occurs, which represents the second step. This release heat is exchanged with a heat sink by solid or liquid conduction.. The third step is the adiabatic unloading of the alloy, which allows the material to undergo the reverse transformation and absorbs heat from the environment, which corresponds to the last step [116, 119-124]. Ideally, the fourth step must comprise an adiabatic transformation, so the system can be cooled by the absorption of heat by the material. Many different prototypes have been developed with the intention to obtain the best efficiency with the cooling capacity using the eC superelastic SMA [118-120, 122, 125]. Parallel to the prototypes studies, many research groups have been developing and studying new elastocaloric alloys. The main target features of these materials is to improve the latent heat of the martensitic transformation without compromise the functionality of the alloy, such as the structural and functional fatigue resistance, which is related to hysteresis and plastic deformation mediated by slip [125-127].

Aiming the improvement of eC in SMA, the change in the transformation entropy $\left(\Delta S_{t}\right)$ under adiabatic conditions should be maximized, so the latent heat of martensitic phase transformation $\left(\Delta H_{\mathrm{t}}\right)$ would also be maximized, since $\Delta S_{\mathrm{t}}=\Delta H_{\mathrm{t}} / T_{0}$ or $\Delta S_{\mathrm{t}}=-\left(\mathrm{d} \sigma_{\mathrm{t}} / \mathrm{d} T\right) \varepsilon_{\mathrm{t}}$, where $T_{0}$ is the equilibrium transformation temperature, $\mathrm{d} \sigma_{\mathrm{t}} / \mathrm{d} T$ is the Clausius-Clapeyron slope and $\varepsilon_{\mathrm{t}}$ is the theoretical transformation strain. Thus, the theoretical temperature change is $\Delta T_{\mathrm{th}}=-\Delta S_{\mathrm{t}}\left(T / C_{\mathrm{p}}\right)$, where $C_{\mathrm{p}}$ is the specific heat capacity and $T$ is the working temperature $[126,127]$. Based on this approach, an alloy with higher entropy change will perform a better cooling capacity. This fact does not strictly happen in practice because during the thermoelastic martensite transformation, hysteretic losses and plastic deformation impairs the full reversibility of the phase transformation, which makes $\Delta T_{\text {th }}$ practically unachievable [33]. In order to access the eC
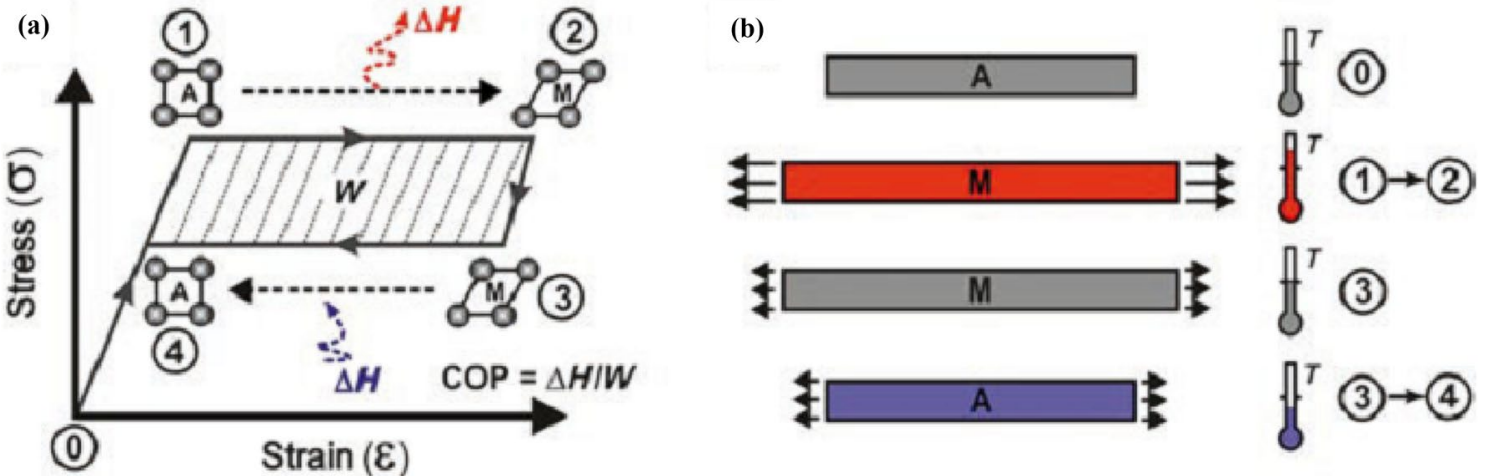

Figure 8: Scheme representing the elastocaloric cycle in a SMA. (a) Four steps of loading and unloading of a superelastic alloy. The latent heat of transformation is released from 1 to 2 and absorbed from 3 to 4. (b) Heat effect of each elastocaloric step. Reprinted from Frenzel et al. [118]. Copyright (2018) by permission from Springer Nature. 

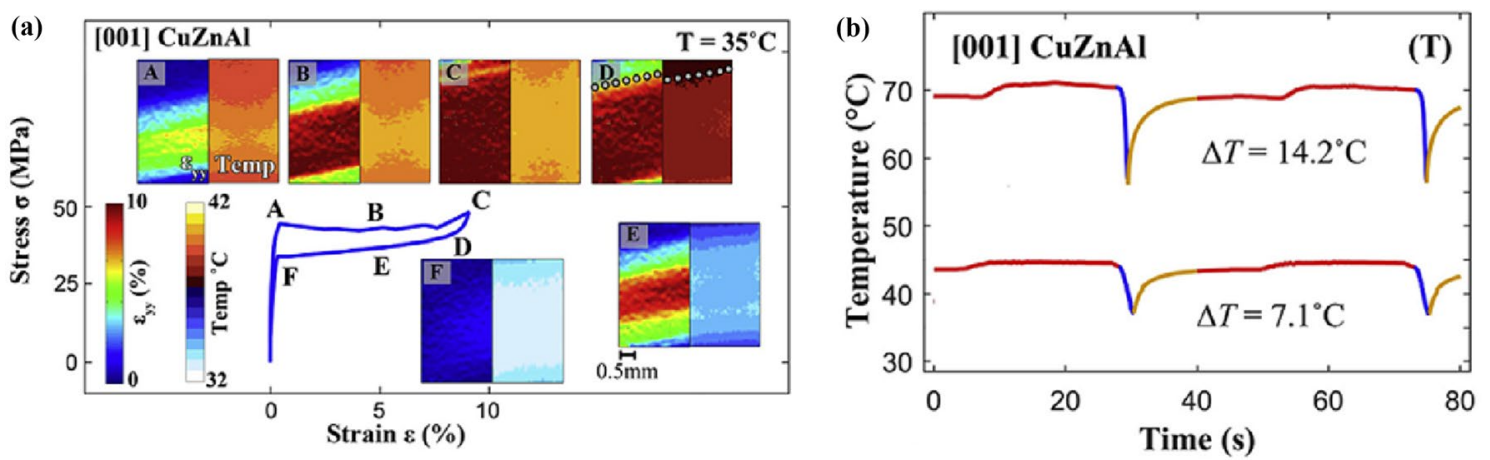

Figure 9: (a) Stress-strain diagram of a Cu-Al-Zn superelastic alloy at $35^{\circ} \mathrm{C}$. The inset figures from $\mathrm{A}$ to $\mathrm{E}$ show the strain measured by the DIC and the temperature measured by infrared camera. (b) Temperature variation versus time during the loading and adiabatic unloading of the same alloy. Adapted from Wu et al. [126]. Copyright (2017) by permission from Elsevier.

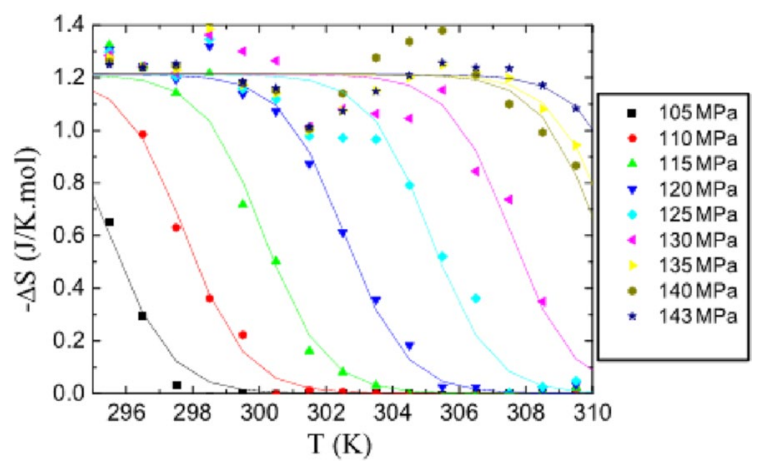

Figure 10: Entropy variation DS during the phase transformation as a function of the temperature or various stress levels of a Cu-Zn-AI SMA. Reprinted from Bonnot et al. [129]. Copyright (2008) by permission from American Physical Society.

parameters in practice, direct and indirect experimental methods are applied. Normally, the indirect experimental methodology for the temperature changes predictions can be carried out indirectly by DSC (Differential Scanning Calorimetry) through the computation of $\Delta H_{\mathrm{t}}$, and/or by the Clausius-Clapeyron slope through the use of uniaxial tests and the calculation of the start stress for stress-induced martensite at various temperatures. Direct measurements of the temperatures changes have been performed by the combination of Digital Image Correlation (DIC) and infrared imaging (IR) in uniaxial superelastic tests [126-128], as can be seen in Fig. 9.

The first significant elastocaloric effect was reported on a $\mathrm{Cu}-\mathrm{Zn}-\mathrm{Al}$ single crystal by Bonnot et al. [129] with a transition entropy-change of $\Delta S_{\mathrm{t}}=1.37 \pm 0.10 \mathrm{~J} / \mathrm{mol} \mathrm{K}$ with a maximum temperature change of $14 \mathrm{~K}$ under a adiabatic condition. Figure 10 shows the stress and strain-induced entropy-change for this alloy at distinct temperatures in a different range of stress (a) and strain (b). This behavior shows that the maximum entropy change $\Delta S$ generally remains unchanged over a broad range of temperatures, representing a promising elastocaloric effect.
In the last decade, many other authors also reported a good elastocaloric effect in the $\mathrm{Cu}-\mathrm{Al}-\mathrm{Zn}$ system $[120,126$, 130-134]. The main findings are related to the adiabatic change temperature $\Delta T$, which ranges around 2 and $20 \mathrm{~K}$, depending on the applied stress, temperature, composition, and grain structures. Also, the temperature span where the $\mathrm{eC}$ takes place in $\mathrm{Cu}-\mathrm{Al}-\mathrm{Zn}$ is generally higher than in other types of caloric materials. One of the most important discovery in this regard was done by Mañosa et al. [132] in a polycrystalline $\mathrm{Cu}_{68} \mathrm{Zn}_{16} \mathrm{Al}_{16}$ (at\%) SMA, which has a working temperature span of $130 \mathrm{~K}$. This large temperature span implicates that the entropy change $\Delta S$ and the temperature change $\Delta \mathrm{T}$ remain over a broad range of temperature, which is a pre-requisite for a good elastocaloric material. Another important results were reported by GràciaCondal et al. [131] in a $\mathrm{Cu}_{68.3} \mathrm{Zn}_{14.2} \mathrm{Al}_{17.5}$ (at\%) single-crystal. They found that the isothermal stress-driven $\Delta S$ saturates at $22 \mathrm{~J} \mathrm{~K}^{-1} \mathrm{~kg}^{-1}$ for an applied compression change of $25 \mathrm{MPa}$ and that the adiabatic temperature change $\Delta T$ increases linearly with compression and is expected to saturate at $15 \mathrm{~K}$ at a compression change of $50 \mathrm{Mpa}$, representing reasonable results for the elastocaloric effects at feasible conditions.

Other promising Cu-based SMA for elastocaloric applications are $\mathrm{Cu}-\mathrm{Al}-\mathrm{Mn}$ SMA [135-141]. In a study published by $\mathrm{Xu}$ et al. [138] it was reported an adiabatic temperature change $\Delta T$ of about $13 \mathrm{~K}$ at a temperature range of $100 \mathrm{~K}$ in a columnar-grained $\mathrm{Cu}_{71.5} \mathrm{Al}_{17.5} \mathrm{Mn}_{11}$ (at\%) SMA. A bamboo-grained $\mathrm{Cu}_{71.1} \mathrm{Al}_{17.2} \mathrm{Mn}_{11.7}$ (at\%) SMA microwires with $\Delta T=11.9 \mathrm{~K}$ under a maximum stress of $400 \mathrm{MPa}$ was reported by Yuan et al. [135]. Also, the same research group studied elastocaloric properties of a heterogenous grained structure $\mathrm{Cu}_{71.1} \mathrm{Al}_{17.2} \mathrm{Mn}_{11.7}$ (at\%) wire [139]. They reported that the local temperature along the wire's axes varied depending on the grains structure during the elastocaloric cycle. Single-crystals and oligocrystals presented a higher temperature change $\Delta T$ due to larger transformation strain for a given applied stress. Polycrystals and single-crystals presented more stable attenuation of $\Delta T$ 
after many elastocaloric cycles in comparison with the other grains structures. These results represent an important step in the understanding of polycrystalline elastocaloric properties.

During the last decade, the development of Cu-based SMA with larger ductility and with transformation temperatures over a large range of temperature have opened an opportunity to develop new caloric materials. The key motivations for researchers are the innumerous challenges to be solved, involving the thermoelastic transformation in $\mathrm{Cu}$-based SMA, the energies involved in the transformation, the role of microstructure, the influence of plastic deformation and the relation between the theoretical temperature change and the real temperature change in an elastocaloric cycle. In the meantime, researchers are also using computational methods using the known thermodynamics properties of these alloys in order to design new and optimized composition for elastocaloric applications [142]. Details of the thermodynamics related to elastocaloric effects can be found in $[120,133,134,143]$. One specific review about other elastocaloric systems can be found in [144].

\section{High temperature shape memory alloys (HTSMA) - Cu-Al-X systems}

Another promising application of $\mathrm{Cu}-\mathrm{Al}$ SMA englobes the high temperature shape memory alloys (HTSMA), which operates above $373 \mathrm{~K}$. Cu-Al SMA have higher transformation temperatures than other $\mathrm{Cu}$-based systems $[7,77,145,146]$. Some $\mathrm{Cu}-\mathrm{Al}-\mathrm{Ni}$ single-crystals presents recoverable strain of about $17 \%$ and shape memory effect above $473 \mathrm{~K}$, which is an outstanding behavior at high temperatures. Normally, $\mathrm{Cu}-\mathrm{Al}$ alloys are more likely to be applied as HTSMA due to their higher transformation temperatures and higher microstructure stability than $\mathrm{Cu}-\mathrm{Zn}$ alloys. On the other hand, the main disadvantage of $\mathrm{Cu}-\mathrm{Al}$ alloys for high temperature applications is the possibility of structural ordering and equilibrium phases' precipitation. As pointed out by Ma et al. [147], although equilibrium phases can be avoided by quenching, this process generates vacancies and prevents the ordering of the alloy. When operating above $373 \mathrm{~K}$, the ordering process would take place and change the transformation temperatures after thermal cycles $[7,51]$. One possible solution to mitigate the effect of transformation temperatures shifting due to ordering process is to age the alloy until complete ordering at a temperature that does not activate the precipitation of the equilibrium phase. Depending on the composition, both temperatures are overlapped so this solution becomes impossible. This is a challenge that motivates researchers in the survey for new compositions of $\mathrm{Cu}$-based SMA. Also, the mechanisms that act at high temperatures, i.e. above $373 \mathrm{~K}$ are subjects of interest.

Many other compositions that operates with good superelasticity and shape memory effect above $373 \mathrm{~K}$ have been developed during the past decades. $\mathrm{Cu}-\mathrm{Al}-\mathrm{Nb}$ [146], $\mathrm{Cu}-\mathrm{Al}-\mathrm{Ni}$ [147], $\mathrm{Cu}-\mathrm{Al}-\mathrm{Ni}-\mathrm{V}$ [92], $\mathrm{Cu}-\mathrm{Al}-\mathrm{Ni}-\mathrm{Mn}[19,47], \mathrm{Cu}-\mathrm{Al}-\mathrm{Ni}-\mathrm{Mn}-\mathrm{Nb}$

[7] are exemples of such systems.

\section{Future perspectives and conclusion remarks}

The recent revival of interest in $\mathrm{Cu}$-based SMA has been motivated by the emerging of novel processing routes, compositions, as well as new methods of characterization and technological applications that demand new SMA.

Considering the processing methods, there are still many possibilities of studies about additive manufacturing in $\mathrm{Cu}$ based SMA. Different additive manufacturing methods as direct metal laser sintering, direct energy deposition, metal binder jetting, were still not explored to fabricate these alloys. Different microstructure and phase formation could be obtained, which can promote different functional and mechanical properties. A systematic investigation of the effect of different scanning strategies and remelting processes during additive manufacturing on the mechanical and functional properties of these alloys as superelasticity, shape recovery, and transformation temperatures, still needs to be carried out. Severe plastic deformation could also be applied to produced layered $\mathrm{Cu}$-based SMA with advanced properties, tunning the transformation temperatures and shape recovery according to application. Functionally graded (FG) Cu-based SMA were also not investigated so far. None of the methods used to produce FG materials as differential heat treatments, additive manufacturing methods, multilayer thin films, powder metallurgy, and surface diffusion have been used for $\mathrm{Cu}$-based SMA so far. These FG materials are very promising to be applied as new sensors and actuators with higher controllability.

In the regarding of SMA compositions covered in this review, it is expected three main approaches to the development of new compositions in a future trend.The first approach is based on the widely used alloying method, which was already described in the present review. This method is performed with the aim to modify and adjust the microstructure and properties of SMA. One example of this approach is the recently reported $\mathrm{Cu}-\mathrm{Al}-\mathrm{Fe}-\mathrm{Mn}$ system, in which a systematic study of the implementation of a fifth alloying element is expected. This procedure has already been started, as discussed previously; however, several alloying elements may be used to modify the microstructure and properties of the SMA of this system. Since this SMA system has a slightly different shape memory effect mechanism, new behaviors can be found by adding another alloying element. The second approach is related to the recent progress and development in manufacturing processes for metallic materials. The improvement of the various fabrication methods that were covered in this review, as well as the creation of new methods, will allow the development of novel SMA with 
improved properties. This trend of development of novel compositions related to technological advances in manufacturing is already observed for the $\mathrm{Cu}-\mathrm{Al}-\mathrm{Mn}$ system as discussed in this review. This approach can also be extrapolated to the well know SMA compositions. In addition, for $\mathrm{Cu}-\mathrm{Al}-\mathrm{Fe}-\mathrm{Mn} \mathrm{SMA}$, the use of different (and new) manufacturing processes may allow different compositions to present the same SME mechanism. The third approach to the development of novel compositions is based on the recent advances in machine learning methods. New compositions can be obtained from a database of different properties of SMA, which, combined with mathematical and thermodynamic formulations, can lead to obtaining not only new SMA compositions but also new SMA systems with optimized microstructures and properties.

One important demand for advanced alloys, including SMA, is for energy applications. Followed by this trend, $\mathrm{Cu}$-based SMA have been considered as high potential materials to be explored in elastocaloric applications. Towards the development of devices with a higher refrigeration capacity, the study of the phase transformation in Cu-based SMA and the mechanisms that affect their latent heat of transformation play an important role in $\mathrm{eC}$. In this context, the key challenge for $\mathrm{Cu}$-based SMA is to find ideal composition and microstructure, aiming to explore the maximum of the transformation energies without implicating in their functionality. Considering that a higher latent heat of transformation generally implies in a higher hysteresis, functional damage after the thermal or stress cycles still limits their application.

In the view of the present article, the authors conclude that very interesting and innovative researches have been performed in $\mathrm{Cu}$-based SMA. With the development of new technologies demanding new materials and functionalities, this class of alloys become important candidates and many researches should still address this topic in the near future.

\section{Acknowledgments}

The authors would like to acknowledge the financial support of CAPES (Coordination for the Improvement of Higher Education Personnel-Brazil) under the program BRAGECRIM (BEX 7185/13-8), FAPESP (São Paulo Research Foundation-Brazil) under the projects 2013/05987-8, and 2017/27031-4 and FAPEMIG grant number APQ-00264-17. Additionally, we would like to thank Professor Claudio Kiminami and Professor Claudemiro Bolfarini for their valuable contributions to the field.

\section{Data availlability}

All data generated or analysed during this study are included in this published article.

\section{Declarations}

Conflict of interest The authors declare no conflict of interest.

\section{Open Access}

This article is licensed under a Creative Commons Attribution 4.0 International License, which permits use, sharing, adaptation, distribution and reproduction in any medium or format, as long as you give appropriate credit to the original author(s) and the source, provide a link to the Creative Commons licence, and indicate if changes were made. The images or other third party material in this article are included in the article's Creative Commons licence, unless indicated otherwise in a credit line to the material. If material is not included in the article's Creative Commons licence and your intended use is not permitted by statutory regulation or exceeds the permitted use, you will need to obtain permission directly from the copyright holder. To view a copy of this licence, visit http://creativecommons.org/ licenses/by/4.0/.

\section{References}

1. J.M. Jani, M. Leary, A. Subic, M.A. Gibson, Mater. Des. 56, 1078-1113 (2014)

2. K. Otsuka, X. Ren, Intermetallics 41, 511-528 (1999)

3. K. Otsuka, C.M. Wayman, Shape Memory Materials (Cambridge University Press, Cambridge, 1998)

4. T. Omori, T. Kusama, S. Kawata, I. Ohnuma, Y. Sutou, Y. Araki, K. Ishida, R. Kainuma, Science 341, 1500 (2013)

5. E.M. Mazzer, C.S. Kiminami, P. Gargarella, R.D. Cava, L.A. Basilio, C. Bolfarini, W.J. Botta, J. Eckert, T. Gustmann, S. Pauly, Mater. Sci. Forum 802, 343-348 (2014)

6. I.N. Qader, M. Kök, F. Dağdelen, Physica B 553, 1-5 (2019)

7. F.R. Milhorato, E.M. Mazzer, Mater. Sci. Eng. A 753, 232-237 (2019)

8. J.P. Oliveira, Z. Zeng, S. Berveiller, D. Bouscaud, F.M.B. Fernandes, R.M. Miranda, N. Zhou, Mater. Des. 148, 145-152 (2018)

9. R. Kainuma, S. Takahashi, K. Ishida, J. Phys. 5, 8-961 (2014)

10. S. Yang, T. Omori, C. Wang, Y. Liu, M. Nagasako, J. Ruan, R. Kainuma, K. Ishida, X. Liu, Sci. Rep. 6, 21754 (2016)

11. R. Dasgupta, A.K. Jain, P. Kumar, S. Hussein, A. Pandey, J. Market. Res. 3, 264-273 (2014)

12. V. Sampath, U.S. Mallik, European Symposium on Martensitic Transformations (ESOMAT), 2009.

13. Y. Chen, C.A. Schuh, Acta Mater. 59, 537-553 (2011)

14. S.M. Ueland, C.A. Schuh, Acta Mater. 60, 282-292 (2012)

15. S.K. Vajpai, R.K. Dube, S. Sangal, Mater. Sci. Eng. A 570, 32-42 (2013)

16. S.K. Vajpai, R.K. Dube, S. Sangal, Mater. Sci. Eng. A 529, 378-387 (2011) 
17. G. Lojen, I. Anžel, A. Kneissl, A. Križman, E. Unterweger, B. Kosec, M. Bizjak, J. Mater. Process. Technol. 162-163, 220-229 (2005)

18. V. Sampath, Smart Mater. Struct. 14, S253-S260 (2005)

19. R.D. Cava, C. Bolfarini, C.S. Kiminami, E.M. Mazzer, W.J.B. Filho, P. Gargarella, J. Eckert, J. Alloys Compd. 615, S602S606 (2014)

20. J. Dutkiewicz, T. Czeppe, J. Morgiel, Mater. Sci. Eng. A 273, 703-707 (1999)

21. J. Lelatko, H. Morawiec, Mater. Sci. Eng. A 481-482, 684-687 (2008)

22. J. Lelatko, H. Morawiec, Mater. Chem. Phys. 81, 472-475 (2003)

23. M.A. Morris, Acta Metall. 40, 1573-1586 (1992)

24. S.M. Ueland, Y. Chen, C.A. Schuh, Adv. Func. Mater. 22, 2094-2099 (2012)

25. S.M. Ueland, Departement of materials science and engineering, Massachusetts institute os technology 2013.

26. S.M. Ueland, C.A. Schuh, Acta Mater. 61, 5618-5625 (2013)

27. D.C. Lagoudas, Shape Memory Alloys - Modeling and Engineering Applications (Springer, New York, 2008)

28. K. Bhattacharya, S. Conti, G. Zanzotto, J. Zimmer, Nature 40, 55-59 (2004)

29. G.B. Olson, M. Cohen, Scr. Metall. 9, 1247-1254 (1975)

30. R.J. Salzbrenner, M. Cohen, Acta Metall. 27, 739-748 (1979)

31. H. Kato, Y. Yasuda, K. Sasaki, Acta Mater. 59, 3955-3964 (2011)

32. L. Sun, W.M. Huang, Z. Ding, Y. Zhao, C.C. Wang, H. Purnawali, C. Tang, Mater. Des. 33, 577-640 (2012)

33. P. Chowdhury, H. Sehitoglu, Prog. Mater Sci. 85, 1-42 (2017)

34. A. Biesiekierski, J. Wang, M.A. Gepreel, C. Wen, Acta Biomater. 8, 1661-1669 (2012)

35. W. Huang, Mater. Des. 23, 11-19 (2002)

36. A. Aydogdu, Y. Aydogdu, O. Adiguzel, J. Mater. Process. Technol. 153-154, 164-169 (2004)

37. V. Recarte, R.B. Pérez-Sáez, E.H. Bocanegra, M.L. Nó, J. SanJuan, Mater. Sci. Eng. A 273, 380-384 (1999)

38. V. Novák, P. Šittner, N. Zárubová, Mater. Sci. Eng. A A234-236, 414-417 (1997)

39. K. Otsuka, H. Sakamoto, K. Shimizu, Acta Metall. 27, 585-601 (1979)

40. T. Waitz, T. Antretter, F.D. Fischer, H.P. Karnthaler, Mater. Sci. Technol. 24, 934-940 (2008)

41. S. Hussain, A. Pandey, R. Dasgupta, Mater. Lett. 240, 157-160 (2019)

42. Y. Sutou, N. Koeda, T. Omori, R. Kainuma, K. Ishida, Acta Mater. 57, 5759-5770 (2009)

43. V. Recarte, R.B. Pérez-Sáez, E.H. Bocanegra, M.L. Nó, J. SanJuan, Metall. Mater. Trans. A. 33A, 2581-2591 (2002)

44. J.I. Pérez-Landazábal, V. Recarte, V. Sánchez-Alarcos, J. Phys. 78, 4223-4236 (2005)
45. J.I. Pérez-Landazábal, V. Recarte, R.B. Pérez-Sáez, M.L. Nó, J. Campo, J.S. Juan, A.P. Letters, Appl. Phys. Lett. 81, 1794 (2002)

46. S. Hussain, P. Kumar, A.K. Jain, A. Pandey, R. Dasgupta, Mater. Perform. Charact. 4, 17 (2015)

47. E.M. Mazzer, P. Gargarella, R.D. Cava, C. Bolfarini, M. Galano, C.S. Kiminami, J. Alloys. Compd. 723, 841-849 (2017)

48. T. Omori, N. Koeda, Y. Sutou, R. Kainuma, K. Ishida, Mater. Trans. 48, 2914-2918 (2007)

49. Y. Sutou, N. Koeda, T. Omori, R. Kainuma, K. Ishida, Acta Mater. 57, 5748-5758 (2009)

50. J. Fornell, N. Tuncer, C.A. Schuh, J. Alloys. Compd. 693, 1205-1213 (2017)

51. E.M. Mazzer, C.S. Kiminami, C. Bolfarini, R.D. Cava, W.J. Botta, P. Gargarella, Thermochim. Acta 608, 1-6 (2015)

52. J. Rodríguez-Aseguinolaza, I. Ruiz-Larrea, M.L. Nó, A. LópezEcharri, E.H. Bocanegra, J.S. Juan, Intermetallics 18, 2183-2190 (2010)

53. Y. Sutou, T. Omori, R. Kainuma, K. Ishida, Acta Mater. 61, 3842-3850 (2013)

54. G.-S. Yang, J.-K. Lee, W.-Y. Jang, Trans. Nonferrous Metals Soc. China 19, 979-983 (2009)

55. R. Dasgupta, J. Mater. Res. 29, 1681-1698 (2014)

56. N. Tuncer, C.A. Schuh, Scr. Mater. 117, 46-50 (2016)

57. A. Agrawal, R.K. Dube, J. Alloys. Compd. 750, 235-247 (2018)

58. G.A. López, I. López-Ferreño, A.R. Kilmametov, T. Breczewski, B.B. Straumal, B. Baretzky, M.L. Nó, J.S. Juan, Mater. Today 2, S747-S750 (2015)

59. B.S. Shariat, Q. Meng, A.S. Mahmud, Z. Wu, R. Bakhtiari, J. Zhang, F. Motazedian, H. Yang, G. Rio, T.-H. Nam, Y. Liu, Mater. Des. 124, 225-237 (2017)

60. K. Otsuka, C.M. Wayman, K. Nakai, H. Sakamoto, K. Shimizu, Acta Metall. 24, 207-226 (1976)

61. T. Kusama, T. Omori, T. Saito, S. Kise, T. Tanaka, Y. Araki, R. Kainuma, Nat. Commun. 8, 354 (2017)

62. J.S. Juan, M.L. Nó, C.A. Schuh, Nat. Nanotechnol. 4, 415-419 (2009)

63. R.D. Cava, C. Bolfarini, C.S. Kiminami, E.M. Mazzer, V.M. Pedrosa, W.J. Botta, P. Gargarella, $22^{\circ}$ CBECiMat - Congresso Brasileiro de Engenharia e Ciência dos Materiais, Natal/Brazil, 2016.

64. T. Gustmann, J.M. dos Santos, P. Gargarella, U. Kühn, J. Van Humbeeck, S. Pauly, Shape Memory Superelasticity 3, 24-36 (2017)

65. P. Gargarella, C.S. Kiminami, E.M. Mazzer, R.D. Cava, L.A. Basilio, C. Bolfarini, W.J. Botta, J. Eckert, T. Gustmann, S. Pauly, Mater. Res. 18, 35-38 (2015)

66. S. Pauly, P. Wang, U. Kühn, K. Kosiba, Addit. Manuf. 22, 753-757 (2018)

67. T. Gustmann, A. Neves, U. Kühn, P. Gargarella, C.S. Kiminami, C. Bolfarini, J. Eckert, S. Pauly, Addit. Manuf. 11, 23-31 (2016) 
68. N. Babacan, S. Pauly, T. Gustmann, Mater. Design 203, 109625 (2021)

69. M.L. Lapér, R. Guimarães, B.R. Barrioni, P.A.P. Silva, M. Houmard, E.M. Mazzer, E.H.M. Nunes, J. Market. Res. 9, 3676-3685 (2020)

70. T. Gustmann, Fakultät Maschinenwesen (Technischen Universität Dresden, Dresden, 2018)

71. T. Gustmann, H. Schwab, U. Kühn, S. Pauly, Mater. Des. 153, 129-138 (2018)

72. M.R. da Silva, P. Gargarella, T. Gustmann, W.J.B. Filho, C.S. Kiminami, J. Eckert, S. Pauly, C. Bolfarini, Mater. Sci. Eng. A 661, 61-67 (2016)

73. B.B. Straumal, A.R. Kilmametov, G.A. López, I. López-Ferreño, M.L. Nó, J.S. Juan, H. Hahn, B. Baretzky, Acta Mater. 125, 274-285 (2017)

74. H.E. da Silva, E.M. Mazzer, Materialia 12, 100712 (2020)

75. P. Zhang, A. Ma, S. Lu, P. Lin, J. Jiang, H. Ma, C. Chu, Mater. Lett. 63, 2676-2679 (2009)

76. S.N. Saud, T.A.A. Bakar, E. Hamzah, M.K. Ibrahim, A. Bahador, Metall. Mater. Trans. A 46, 3528-3542 (2015)

77. E.M. Mazzer, C.S. Kiminami, C. Bolfarini, R.D. Cava, W.J. Botta, P. Gargarella, F. Audebert, M. Galano, Mater. Sci. Eng. A 663, 64-68 (2016)

78. T. Gustmann, J.M. dos Santos, P. Gargarella, U. Kühn, J. Van Humbeeck, S. Pauly, Shape Memory Superelasticity 3, 24-36 (2016)

79. D.B. Gera, J. Soyama, R.D. Cava, J.E. Spinelli, C.S. Kiminami, Adv. Eng. Mater. 20, 1800372 (2018)

80. M.A. Morris, Acta Metall. Mater. 40(7), 1573-1586 (1992)

81. J.W. Kim, D.W. Roh, E.S. Lee, Y.G. Kim, Metall. Trans. A 21, 741-744 (1990)

82. S.N. Saud, E. Hamzah, T. Abubakar, M. Zamri, M. Tanemura, J. Therm. Anal. Calorim. 118, 111-122 (2014)

83. Z. Deng, H. Yin, C. Zhang, W. Li, Mater. Sci. Eng. A 803, 140472 (2021)

84. S.N. Saud, E. Hamzah, T. Abubakar, H.R. Bakhsheshi-Rad, S. Farahany, A. Abdolahi, M.M. Taheri, J. Alloys. Compd. 612, 471-478 (2014)

85. X. Zhang, T. Cui, X. Zhang, Q. Liu, Z. Dong, C. Man, J. Alloys Compd. 858, 157685 (2021)

86. X. Zhang, J. Sui, Q. Liu, W. Cai, Mater. Lett. 180, 223-227 (2016)

87. S.N. Saud, E. Hamzah, H.R. Bakhsheshi-Rad, T. Abubakar, Scanning 2017, 1789454 (2017)

88. S.N. Saud, E. Hamzah, T. Abubakar, S. Farahany, J. Mater. Eng. Perform. 23, 255-261 (2013)

89. M. Kök, K. Yildiz, Appl. Phys. A 116, 2045-2050 (2014)

90. M. Zare, M. Ketabchi, J. Therm. Anal. Calorim. 127, 21132123 (2016)

91. P. Ochin, A. Dezellus, P. Plaindoux, J. Pons, P. Vermaut, R. Portier, E. Cesari, Acta Mater. 54, 1877-1885 (2006)
92. X. Zhang, Q. Liu, Intermetallics 92, 108-112 (2018)

93. S.N. Saud, E. Hamzah, T. Abubakar, H.R. Bakhsheshi-Rad, M.N. Mohammed, Metall. Mater. Trans. A 47, 5242-5255 (2016)

94. R. Kainuma, S. Takahashi, K. Ishida, Metall. Mater. Trans. A 27, 2187-2195 (1996)

95. S. Xu, T. Kusama, X. Xu, H. Huang, T. Omori, J. Xie, R. Kainuma, Materialia 6, 100336 (2019)

96. J.P. Oliveira, B. Panton, Z. Zeng, T. Omori, Y. Zhou, R.M. Miranda, F.M.B. Fernandes, Mater. Design 90, 122-128 (2016)

97. R. Kainuma, Mater. Trans. 59, 327-331 (2018)

98. S.K. Tanaka, T. Omori, R. Kainuma, K. Ishida, Materia (Rio J.) 51, 108-110 (2012). ((in Japanese))

99. Q. Wang, F. Han, J. Wu, G. Hao, Mater. Lett. 61, 2598-2600 (2007)

100. X. Ji, Q. Wang, F. Yin, C. Cui, P. Ji, G. Hao, Compos. A Appl. Sci. Manuf. 107, 21-30 (2018)

101. J. Yang, Q.Z. Wang, F.X. Yin, C.X. Cui, P.G. Ji, B. Li, Mater. Sci. Eng. A 664, 215-220 (2016)

102. X. Lu, F. Chen, W. Li, Y. Zheng, J. Alloys. Compd. 480, 608-611 (2009)

103. A. Pandey, S. Hussain, P. Nair, R. Dasgupta, J. Alloys Compds 836, 155266 (2020)

104. S. Yang, M. Chi, J. Zhang, K. Zhang, X. Liu, C. Wang, X. Liu, Mater. Sci. Eng. A 739, 455-462 (2019)

105. C.A. Canbay, S. Gudeloglu, Z.K. Genc, Int. J. Thermophys. 36, 783-794 (2015)

106. C.A. Canbay, O. Karaduman, N. Ünlü, S.A. Baiz, İ Özkul, Compos. B 174, 106940 (2019)

107. C.A. Canbay, A. Tataroğlu, A. Dere, A.G. Al-Sehemi, A. Karabulut, A. Bektaş, A.A. Al-Ghamdi, F. Yakuphanoglu, Mater. Sci. Eng. B 264, 114931 (2021)

108. S. Montecinos, M.O. Moroni, A. Sepúlveda, Mater. Sci. Eng. A 419, 91-97 (2006)

109. G.B. Narasimha, S.M. Murigendrappa, Mater. Sci. Eng. A 755, 211-219 (2019)

110. V.H.C. de Albuquerque, T.A.D.A. Melo, R.M. Gomes, S.J.G. de Lima, J.M.R.S. Tavares, Mater. Sci. Eng. A 528, 459-466 (2010)

111. V.H.C. de Albuquerque, T.A.D.A. Melo, D.F. de Oliveira, R.M. Gomes, J.M.R.S. Tavares, Mater. Des. 31, 3275-3281 (2010)

112. G.V.M. da Candido, T.A.A. de Melo, V.H.C. De Albuquerque, R.M. Gomes, S.J.G. de Lima, J.M.R.S. Tavares, J. Mater. Eng. Perform. 21, 2398-2406 (2012)

113. T. Kalinga, S.M. Murigendrappa, S. Kattimani, J. Mater. Eng. Perform. 48, 1-11 (2021)

114. B.H.D.S. Andrade, R.E. Caluête, D.F. de Oliveira, R.M. Gomes, T.A.D.A. Melo, J. Thermal Anal. Calorim. 139, 905-911 (2019)

115. ŞN. Balo, M. Ceylan, J. Mater. Process. Technol. 124(1-2), 200-208 (2002)

116. L. Mañosa, A. Planes, M. Acet, J. Mater. Chem. A 1, 4925 (2013) 
117. M. Schmidt, A. Schütze, S. Seelecke, APL Mater. 4, 064107 (2016)

118. J. Frenzel, G. Eggeler, E. Quandt, S. Seelecke, M. Kohl, MRS Bull. 43, 280-284 (2018)

119. H. Ossmer, M. Kohl, Nat. Energy 1, 1-2 (2016)

120. J. Tušek, K. Engelbrecht, R. Millán-Solsona, L. Mañosa, E. Vives, L.P. Mikkelsen, N. Pryds, Adv. Energy Mater. 5, 1500361 (2015)

121. X. Moya, S. Kar-Narayan, N.D. Mathur, Nat. Mater. 13, 439-450 (2014)

122. K. Engelbrecht, J. Phys. 1, 021001 (2019)

123. S. Qian, Y. Wang, L. Yuan, J. Yu, Energy 182, 881-899 (2019)

124. D. Cong, W. Xiong, A. Planes, Y. Ren, L. Manosa, P. Cao, Z. Nie, X. Sun, Z. Yang, X. Hong, Y. Wang, Phys. Rev. Lett. 122, 255703 (2019)

125. S. Qian, L. Yuan, J. Yu, G. Yan, Energy 141, 744-756 (2017)

126. Y. Wu, E. Ertekin, H. Sehitoglu, Acta Mater. 135, 158-176 (2017)

127. H. Sehitoglu, Y. Wu, E. Ertekin, Scr. Mater. 148, 122-126 (2018)

128. G.J. Pataky, E. Ertekin, H. Sehitoglu, Acta Mater. 96, 420-427 (2015)

129. E. Bonnot, R. Romero, L. Manosa, E. Vives, A. Planes, Phys. Rev. Lett. 100, 125901 (2008)

130. S. Qian, Y. Geng, Y. Wang, T.E. Pillsbury, Y. Hada, Y. Yamaguchi, K. Fujimoto, Y. Hwang, R. Radermacher, J. Cui, Y. Yuki, K. Toyotake, I. Takeuchi, Philos. Trans. Ser. A 374, 2-8 (2016)

131. A. Gràcia-Condal, E. Stern-Taulats, A. Planes, E. Vives, L. Mañosa, Phys. Status Solidi B 255, 1700422 (2018)

132. L. Mañosa, S. Jarque-Farnos, E. Vives, A. Planes, Appl. Phys. Lett. 21, 2013 (1904)
133. L. Manosa, A. Planes, Adv. Mater. 29, 1603607 (2017)

134. J. Tušek, K. Engelbrecht, L. Mañosa, E. Vives, N. Pryds, Shape Memory Superelasticity 2, 317-329 (2016)

135. B. Yuan, S. Zhong, M. Qian, X. Zhang, L. Geng, J. Alloys Compd. 850, 156612 (2021)

136. B. Yuan, X. Zhu, X. Zhang, M. Qian, J. Mater. Sci. 54, 9613-9621 (2019)

137. B. Yuan, M. Qian, X. Zhang, M. Imran, L. Geng, Int. J. Refrig 114, 54-61 (2020)

138. S. Xu, H. Huang, J. Xie, S. Takekawa, X. Xu, T. Omori, R. Kainuma, APL Mater. 4, 106106 (2016)

139. B. Yuan, M. Qian, X. Zhang, L. Geng, Scr. Mater. 178, 356-360 (2020)

140. N.-H. Lu, C.-H. Chen, Mater. Sci. Eng. A 800, 140386 (2021)

141. H. Wang, H.-Y. Huang, Y.-J. Su, J. Alloys Compd. 828, 154265 (2020)

142. X.-P. Zhao, H.-Y. Huang, C. Wen, Y.-J. Su, P. Qian, Comput. Mater. Sci. 176, 109521 (2020)

143. J. Tan, Y. Wang, S. Xu, H. Liu, S. Qian, Energy 197, 117261 (2020)

144. M. Imran, X. Zhang, Mater. Des. 195, 109030 (2020)

145. E.M. Mazzer, P. Gargarella, C.S. Kiminami, C. Bolfarini, R.D. Cava, M. Galano, J. Mater. Res. 32, 3165-3174 (2017)

146. J. Ma, I. Karaman, R.D. Noebe, Int. Mater. Rev. 55, 257-315 (2013)

147. I. López-Ferreño, J.F. Gómez-Cortés, T. Breczewski, I. Ruiz-Larrea, M.L. Nó, J.M.S. Juan, J. Mater. Res. Technol. 9, 9972-9984 (2020) 